\title{
PRODUÇÃO DO BAGAÇO DE CANA-DE-AÇÚCAR (Sacharum sp. L.) AUTO-HIDROLISADO E AVALIAÇĀO DO SEU VALOR NUTRITIVO PARA RUMINANTES
}

\author{
RICARDO BURGI \\ Engenteiro Agrônomo
}

Orientador: Prof. Dr. RAUL DANTAS D'ARCE

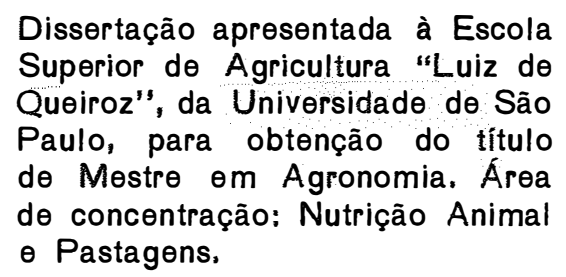

PIRACICABA

Estado de São Paulo - Brasil

Novembro - 1985 
i.

Aos meus pais

LYDIA $\mathrm{e}$ URS

DEDICO . 


\section{HOMENAGEM ESPECIAL}

Ao Engo LAMARTINE NAVARRO Jr., presidente da Destilaria Alcidia S/A, pioneiro e per tinaz incentivador desta pesquisa. 
AGRADECIMENTOS

Ao Prof.Dr. Raul Dantas d'Arce, pela orientação dedicada, incentivo e amizade.

Ao Prof.Dr. Wilson Roberto Soares Mattos, pelo apoio, sugestões e orientação nas análises laboratoriais.

Ao Prof.Dr. Vidal Pedroso de Faria, pelas sugestões no desenvolvimento do trabalho.

Ao Prof.Dr. Irineu Umberto Packer, pelo auxilio na análise estatistica e interpretação dos resultados.

Ao Prof.Dr. Henrique Vianna de Amorim, pelo apoio no inicio deste trabalho.

Ao Engo Agro Mário Celso Fernandes Lacorte, pela cooperação e amizade.

A Técnica de Laboratório Ana Maria Zani de Moura, pela presteza nas análises laboratoriais.

A Estagiária Maristela Neves Conceição, pelo auxilio no preparo de amostras para análise.

A Destilaria Alcidia S/A, de Teodoro Sampaio - S.P., que patrocinou' este trabalho.

Aos Engo Marcelo Camargo Pacheco Filho, Engo Agro Roque Ge rônimo Herrera e Sr. Donato Cinto, da Destilaria Alcidia S/A, pela colaboração e amizade. 
2. REVISÃO DE LITERATURA 4

2.1. A fração fibrosa das plantas forrageiras $\ldots \ldots \ldots \ldots \ldots \ldots \ldots \ldots$

2.1.1. Os compostos polimerizados da parede celular

2.1.2. A estrutura da parede celular $\ldots \ldots \ldots \ldots \ldots \ldots$

2.1.3. A parede celular e o valor nu tritivo da planta forrageira.

2.1.4. Valor nutritivo do bagaço de cana..$\ldots \ldots \ldots \ldots \ldots \ldots$

2.2. Métodos de tratamento de forragens

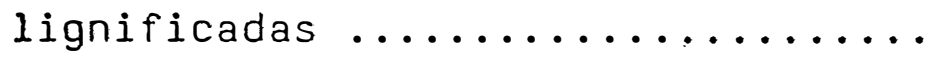

2.2.1. Tratamentos quimicos ........

2.2.2. Tratamentos biológicos ......

2.2.3. Tratamentos físicos ........

2.3. o processo de auto-hidrólise .......

2.3.1. Efeitos do tratamento sobre o valor nutritivo da forragem. 
Página

2.3.2. Resultados com animais.......

3. MATERIAIS E MÉTODOS $\ldots \ldots \ldots \ldots \ldots \ldots \ldots$

3.1. Otimização e padronização do processo

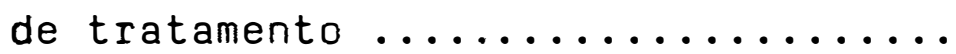

3.2. Testes de consumo $\ldots \ldots \ldots \ldots \ldots \ldots$

3.3. Experimento com bovinos confinados ..

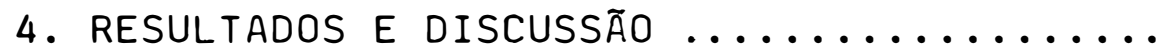

4.1. Padronização do processo de tratamento $\ldots \ldots \ldots \ldots \ldots \ldots \ldots \ldots$

4.2. Testes de consumo $\ldots \ldots \ldots \ldots \ldots \ldots$

4.3. Experimento com bovinos confinados ..

5. CONCLUSÕES $\ldots \ldots \ldots \ldots \ldots \ldots \ldots \ldots \ldots \ldots$ 


\section{LISTA DE TABELAS}

Página

1 - Constituintes fibrosos e digestibilidade "in vitro" da matéria seca e celulose do Capim Napier em sete estádios de crescimento. (SIL VEIRA, 1971)

2 - Resultados de tratamentos com pressão de vapor sobre a digestibilidade "in vitro" da ma téria seca (DIVMS) do bagaço de cana........

3 - Composição das rações completas do 10 teste de consumo (\% da matéria original)

4 - Composição das rações completas do 20 teste de consumo (em \% da matéria original)

5 - Composição das rações completas (\% da maté ria original) do experimento com bovinos con. finados

6 - Digestibilidade verdadeira "in vitro" da matéria seca (DVIVMS) do bagaço auto-hidrolisą do em função da pressão e do tempo de tratamento 
vii.

Página

7 - Tratamento padronizado do bagaço de cana com aplicação de vapor d'água sob pressão de 17 $\mathrm{kgf} / \mathrm{cm}^{2}$ durante 5 minutos (obtenção do $\mathrm{BAH}$ 17/5)

8 - Resultados médios de análises bromatológicas do BAH $17 / 5$ e do bagaço "in natura" ........

9 - Consumo de matéria seca como porcentagem do peso vivo de bovinos alimentados com rações completas à base de BAH $17 / 5 \ldots \ldots \ldots \ldots \ldots$

10 - Resultados das análises bromatológicas dos alimentos das rações completas

11 - Porcentagem dos alimentos na matéria seca das rações completas à base de BAH $17 / 5$ ou bagaço "in natura"..................

12 - Resultados das análises bromatológicas das rações completas à base de $B A H 17 / 5$ ou baga-

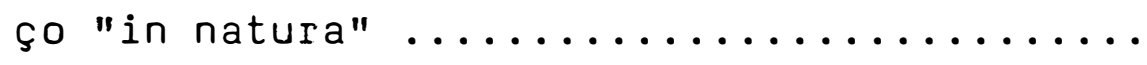


viii.

Página

13 - Consumo médio diário das rações completas (kg/cab.dia) à base de BAH $17 / 5$ ou bagaço

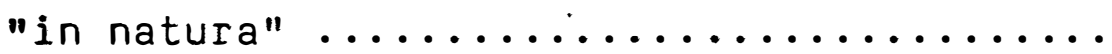

14 - Resultados das pesagens dos bovinos alimentados com rações completas à base de BAH $17 / 5$ ou bagaço "in natura" .............

15 - Resultados de ganho de peso dos bovinos ali mentados com rações completas à base de BAH

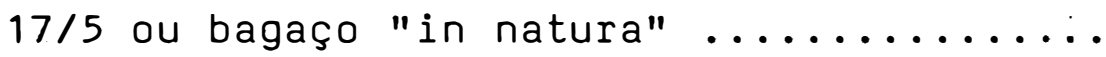

16 - Parâmetros de eficiência nutricional dos bo vinos alimentados com as rações completas à base de BAH $17 / 5$ ou bagaço "in natura".... 


\section{LISTA DE FIGURAS}

Página

1 - Vista com exposição das diferentes camadas da parede celular, mostrando a organização das microfibrilas de celulose em cada uma delas. (Segundo A.Wardrop e D.Bland, 1959, citados

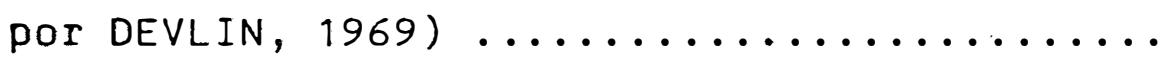

2 - Efeito da maturação sobre a. MS de componentes

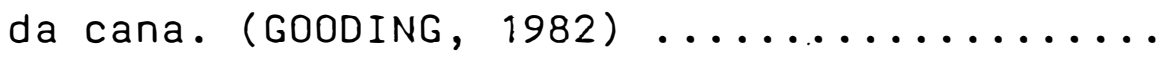

3 - Efeito da pressão e tempo de tratamento sobre a digestibilidade do bagaço de cana. (TAYLOR

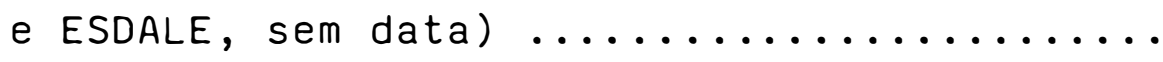

4 - 0 equipamento de auto hidrólise. (Cap.: 400

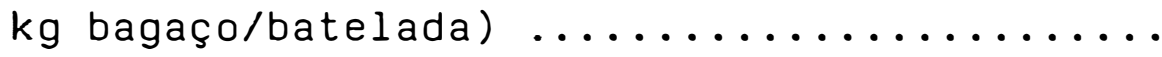

5 - Digestibilidade verdadeira "in vitro" da maté ria s'eca (.DVIVMS) do bagaço hidrolisado em função da pressão e do tempo de tratamento 
6 - Consumo em função da proporção de BAH $17 / 5$ na ração completa

7 - Evolução do consumo das rações completas à bạ se de $\mathrm{BAH} 17 / 5$ ou bagaço "in natura"......... 
PRODUÇÃO DO BAGAÇO DE CANA-DE-AÇÚCAR (Saccharum SP. L.)

AUTO-HIDROLISADO E AVALIAÇÃO DO SEU VALOR NUTRITIVO

PARA RUMINANTES

Candidato: RICARDO BÜRGI

Orientador: Prof.Dr. Raul Dantas d'Arce

RESUMO

o processo de auto-hidrólise consiste em subme ter material ligno-celulósico a tratamento com pressão de vapor, para melhorar o seu valor nutritivo, como alimento para ruminantes.

A aplicação do processo no tratamento do bagaço de cana foi otimizada operacionalmente e o material obtido foi avaliado como alimento para bovinos confinados.

o tratamento foi padronizado com pressão de $17 \mathrm{kgf} / \mathrm{cm}^{2}$ e tempo de 5 minutos, o que elevou a digestibilida de "in vitro" da MS de 35,31\%, no bagaço "in natura", para $64,82 \%$ no material tratado, denominado $\mathrm{BAH}$ 17/5. Em um teste preliminar obteve-se consumo diário médio de $2,9 \mathrm{~kg}$ matéria se ca/100 kg peso vivo, quando se forneceu uma ração completa con tendo $74 \%$ de $B A H 17 / 5$ na MS. 
Em um experimento de ganho de peso com bovinos confinados $(\bar{P} \bar{V}$ inicial $=330 \mathrm{~kg})$ durante 84 dias, O BAH 17/5 foi fornecido nos niveis de 40\%, 50\% e 60\% da MS de rações com pletas (Rações 40, 50 e 60), formuladas para proporcionar ganho de peso de $1 \mathrm{~kg} / \mathrm{dia}$. Um lote testemunha recebeu ração com pleta com $60 \%$ de bagaço "in natura" na MS (Ração $60 \mathrm{~T}$ ). As quatro rações completas continham $70 \%$ de volumoso na MS (baga ço + cana picada) e $30 \%$ de uma mistura de concentrados.

O ganho de peso médio ( $g / d i a)$ e o consumo de MS (kg/cabeça.dia) foram 960,816,872, 699;9,92, 10,00,10,13 e 6,71 para os lotes recebendo as Rações $40,50,60$ e $60 \mathrm{~T}$ respectivamente.

Houve um periodo de $3-4$ semanas até que ocorresse a estabilização do consumo das rações completas à base de BAH 17/5. Após esse periodo o ganho de peso médio (g/dia) e o consumo de MS (kg/cabeça.dia) foram 981, 937, 1.160, 613; $11,17,11,36,11,77$ e 7,19 , respectivamente.

As rações à base de BAH $17 / 5$ proporcionaram ganhos de peso significativamente superiores $(p<0,01)$ em rela ção a Ração $60 \mathrm{~T}$. Não houve efeito de niveis de BAH $17 / 5$ sobre o ganho de peso dos bovinos. 
xiii.

Conclui-se que o processo de auto-hidrólise é viável para o tratamento do bagaço e que o material obtido po de ser fornecido como componente principal de rações comple tas para bovinos confinados. 


\section{AUTO-HYDROLYSIS OF THE SUGAR CANE BAGASSE AND ITS FEEDING VALUE FOR RUMINANTS.}

\section{Candidate: RICARDO BURGI \\ Adviser: Prof.Dr. Raul Dantas d'Arce}

\section{SUMMARY}

The auto-hydrolysis process consists in treating ligno-cellulosic materials under steam-pressure to rupture the fiber structure and to improve its nutritive value for ruminants.

The effects of treatment pressure and time on sugarcane bagasse digestibility were evaluated to establish the operational patterns. The operational conditions adopted were $17 \mathrm{kgf} / \mathrm{cm}^{2}$ and 5 minutes. The "in vitro" DM digestibility of the treated bagasse obtained under these.conditions (BAH 17/5) was increased from $35.31 \%$ (untreated bagasse) to $64.82 \%$.

In a preliminary 40 days trial with confined steers weighing $300 \mathrm{~kg}$ the mean intake reached $2,9 \mathrm{~kg}$ dry matter $(D M) / 100 \mathrm{~kg}$ body weight, when the animals were fed a complete ration containing $74 \% \mathrm{BAH} 17 / 5$, on a DM basis. 
In a 84 days feed lot trial (initial body weight $=330 \mathrm{~kg}), \mathrm{BAH} 17 / 5$ was fed at levels of $40 \%, 50 \%$ and $60 \%$ in complete rations (Rations 40,50 and 60 , respectively) formulated to allow I kg dayly gain. A control lot was fed a complete ration formulated with $60 \%$ untreated bagasse (on DM basis - Ration $60 \mathrm{~T}$ ). The four complete rations were $70 \%$ roughage (bagasse + chopped sugarcanẻ stalks) and $30 \%$ a concen trate mixture.

The average body weight gain (g/day) and the DM intake (kg/day) were 960,816,872,699;9.92, 10.00, 10.13 and 6.71 for the lots on Rations 40, 50, 60 and $60 \mathrm{~T}$, respecti vely.

It was necessary 3-4 weeks to achieve maximum intake level (as \% of body weight) with the BAH 17/5 rations. After this adaptation period, the average dayly gain (g/day) and DM intake (kg/day) were 981, 931, 1,160,613; 11.17, 11.36, 11.77 and 7.19 , respectively.

The $\mathrm{BAH} 17 / 5$ rations were significantly $(p<0,01)$ superior than the untreated bagasse ration. There was no significant BAH $17 / 5$ level effect on body weight gain.

It may be concluded that the auto-hydrolysis process is a feasibile one to improve the nutritive value of 
$x \vee i$

the surplus bagasse from the sugarcane industry and that it can be used as the major roughage constituent of complete rations in feedlot. 


\section{INTRODUÇÃO}

A rápida expansão da indústria alcooleira, nos últimos anos, gerou quantidades crescentes de residuos e subprodutos, estimulando o interesse dos empresários por soluções que possam proporcionar seu aproveitamento econômico. 0 bagaço de cana é atualmente o maior residuo da agro-indústria brasileira, sendo que as sobras da safra de 1984 foram estimadas em cerca de sete milhões de toneladas (PINTO, 1983), que se acumularam nos páteos de usinas e destilarias.

Soluções para o problema vêm sendo estudadas em diversos campos da pesquisa. Existem processos, em diferentes estágios de desenvolvimento, para utilização do bagaço de cana como fonte de energia em substituição ao óleo combustivel; como matéria-prima na produção de chapas aglomeradas e de furfural; como substrato para fermentação alcoólica, após delignifi cação e despolimerização da celulose, e muitos outros usos (ZE GARRA, 1978). Contudo, as opções já técnica e economicamente 
aprovadas para utilização comercial são poucas e restritas a áreas próximas às usinas e destilarias. Entre outros fatores, a baixa densidade do bagaço de cana, aliado a um reduzido valor comercial, limitam seu transporte a médias e largas distâncias.

A transformação do bag̉aço de cana em alimento para ruminantes representa uma opção especialmente interessante para regiões onde a cultura da cana deslocou a atividade pecuária, ocupando áreas antes cobertas por pastagens. Conside rando que a safra de cana coincide com a época de seca, em que há escassêz de forragens, esta opção de utilização do bagaço assume uma importância adicional, uma vez que pode contribuir para a redução da flutuação de oferta de alimento essenciais como a carne e o leite.

Diversos pesquisadores conduziram trabalhos vi.. sando avaliar o valor nutritivo do bagaço de cana "in natura " para animais ruminantes e concluíram que sua utilização na die ta é limitada devido à elevada lignificação da fração fibrosa e à baixa densidade, que prejudicam a digestibilidade e o consumo. O désenvölvimento de processos para o tratamento do baga ço de cana, visando aumentar seu vaior nutritivo e o potencial de utilização em rações para bovinos, vem despertando o inte resse de empresários do setor sucro-alcooleiro, empenhados na adoção de sistemas integrados de produção. O processo de au- 
to-hidrólise destaca-se entre os demais pela facilidade de in talação e operação dentro de usinas e destilarias, simplici dade dos equipamentos e por demandar um único insumo, abundante nessas indústrias, que é o vapor d'água sob pressão.

Utilizando equipamentos desenvolvidos pela Destilaria Alcidia S/A, de Teodor Sampaio-SP, este trabalho teve por objetivos otimizar o processo de auto-hidrólise e avaliar seus efeitos sobre a composição e o valor nutritivo do bagaço de cana. 
2. REVISÃO DA LITERATURA

2.1. A fração fibrosa das plantas forrageiras

As substâncias componentes de uma planta forrageira podem ser separadas em conteúdo celular e constituintes da parede celular. Essa classificação, proposta por Van SOEST e MOORE (1965), objetiva facilitar a estimativa do valor nutritivo das plantas forrageiras e materiais fibrosos de origem vegetal utilizados no arraçoamento de animais.

No conteúdo celular estão presentes os carboidra tos solúveis, o amido, quase toda a proteína, minerais solúveis, lipidios e os ácidos orgânicos das plantas. Rompidas as paredes ce lulares, estas substâncias podem ser integralmente aproveitadas no trato digestivo dos animais vertebrados. 
A parede celular responsável pela estrutura e sustentação dos vegetais e entre seus constituintes destacam-se quantitativamente três compostos polimerizados a celulose, a hemicelulose e a lignina - ligados entre si covalentemente e formando longas cadeias, que em essência com põem a fração fibrosa das plantas. Pectinas, ceras, minerais, cutina, alguma proteína e compostos nitrogenados são substân-. cias que se apresentam em proporções reduzidas na parede ce lular e são nutricionalmente menos importantes (Van SOEST, 1982 ).

2.1.1. Os compostos polimerizados da parede celular

A celulose e a hemicelulose são polissacarideos. Uma molécula de celulose é um longo e flexivel homopolí mero de moléculas de glucose unidas por ligações covalentes beta 1-4. A hemicelulose, ao contrário, não é uma substância quimicamente definida, mas um heteropolissacarídeo com uma cadeia central de pentoses (xilose, nas gramineas) e cadeias laterais contendo hexoses (MC DONALD et alii 1977). São compostos higroscópicos, especialmente a hemicelulose.

Sessenta por cento das moléculas de celulose es tão unidas entre si nas diferentes camadas da parede celular, formando uma estrutura cristalina de fibrilas e microfibrilas (GOSSELINK, 1982). O restante da celulose (celulose amorfa) e 
a hemicelulose preenchem parcialmente os vazios existentes nas camadas da parede celular,constituindo-se na matriz das microfibrilas de celulóse. A celulose e a hemicelulose não são degradadas pelas enzimas digestivas dos vertebrados, porém podem ser consideravelmente digeridas pelas bactérias que habitam o rúmem de animais poligástricos e pela microflora intestinal de outros herbivoros.

A lignina é um polímero aromático amorfo e não higroscópico. O termo lignina representa uma série de compostos estreitamente relacionados, cuja estrutura ainda não é perfeitamente conhecida. Aceita-se que a lignina apresenta uma estru tura polimerizada em cadeia tridimensional cuja unidade básica é o fenil-propano (Van SOEST, 1982; MC DONALD et alii 1977). A lignina é muito resistente à degradação química e, por isso quase não sofre digestão enzimática. A medida que as plantas amadurecem, ocorre deposição de lignina na parede celular. A lignina incrusta-se nas camadas da parede celular formando com plexas ligações com a celulose e a hemicelulose, o que diminui a digestibilidade destas. A ligação com a celulose é provável, mas ainda não foi caracterizada (Van SOEST, 1982). A ligação com a hemicelulose é a mais importante e constitui-se, no caso de gramíneas, da esterificação de um radical acetil da lignina com a xilose da hemicelulose (Waagepetersen, 1979 citado por GOSSELINK, 1982). 


\subsubsection{A estrutura da parede celular}

A estrutura da parede celular é complexa,con forme é mostrado na Figura 1.

A parede celular de uma célula madura apresenta quatro camadas distintas: a pafede primária e as camadas exter na (S1), intermediária (S2) e interna (S3) da parede secundá ria. Separando duas células adjacentes existe uma substância rica em pectato de cálcio, denominada lamela média e que fun ciona como um agente cimentante (DEVLIN, 1969).

A unidade básica da estrutura das camadas da pa rede celular é a microfibrila de celulose, que tem diâmetro de aproximadamente $62.500 \AA$. Esta é composta de cerca de 20 fí brilas elementares ou micelas. Cada micela é constituida de aproximadamente 100 cadeias moleculares de celulose.

A organização das microfibrilas de celulose é diferente nas paredes primária e secundária. Na parede primá ria, as microfibrilas apresentam-se dispostas de forma desorde nada, transversalmente ao eixo celular, à exceção dos vértices celulares onde a orientação é longitudinal. A parede primária é elástica e permite o elongamento celular. A medida que a cé lula envelhece, ocorre a formação das camadas da parede secundária e isto confere rigidez à parede celular. 


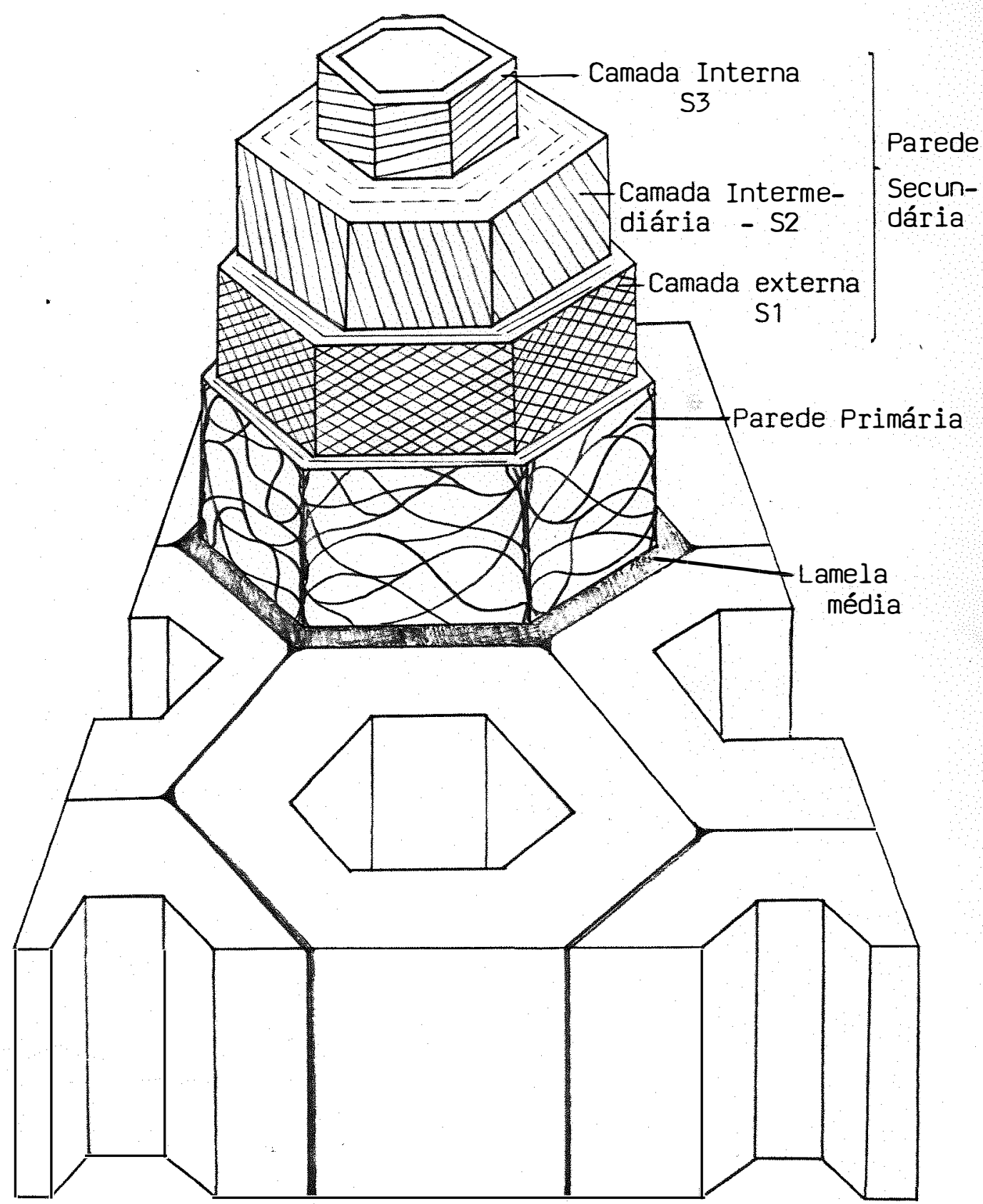

Figura 1 - Vista com exposição das diferentes camadas da parede celular,mostrando a organização das microfibrilas de celulose em cada uma delas.

(Segundo A.Wardrop e D.Bland,1959, citados por DEVLIN, 1969). 
Nestas camadas, a organização das microfibri las segue um arranjo definido (DEVLIN, 1969). Na camada externa ( $\mathrm{S} 1$ ) as microfibrilas dispõem-se segundo duas espirais opostas, que formam um ângulo aberto com o eixo celular. Na camada intermediária (S2) observa-se uma espiral em ângulo agu do com o eixo celular e anéis concêntricos de microfibrilas. $\mathrm{Na}$ camada interna (S3) as microfibrilas dispõem-se segundo uma helicóide suave.

2.1.3. A parede celular e o valor nutritivo da planta forrageira

o valor nutritivo das plantas forrageiras é determinado por dois fatores: a proporção de parede celular e o seu grau de lignificação (Van SOEST, 1982).

Os animais ruminantes, através dos simbiontes estomacais, aproveitam uma parte considerável da fração fibrosa de folhas e colmos novos das plantas, cuja parede celular apresenta as microfibrilas de celulose envoltas numa matriz não lignificada, composta de celulose e hemicelulose (Mc DONALD et alii 1977). As plantas maduras, devido à deposição de lignina na matriz das camadas da parede secundária, apresen tam menor digestibilidade, pois a lignina, além de indigerivel, constitui uma barreira física que dificulta a exposição de celulose e hemicelulose ao ataque dos microorganismos do rúmen. 
Com o amadurecimento dos tecidos da planta, a parede secundária engrossa, devido à deposição de lignina, adquirindo extrema rigidez. Isto ocorre às expensas do espaço intracelular, pois o tamanho da célula é determinado quando o tecido ainda é novo (Van SOEST, 1982). A proporção de conteú do celular é então reduzida, o que concorre para diminuir ain da mais a digestibilidade da forragem.

A Tabela 1 mostra o efeito da maturação daplan ta forrageira sobre os constituintes fibrosos e a digestibili dade "in vitro" da matéria seca. Com a maturação aumenta o teor de fibra, especialmente a lignina, e a digestibilidade cai.

A cana-de-açúcar madura, conforme a variedade, apresenta teor de lignina e de parede celular variando de $4,5 \%$ a $8,4 \%$ e de $43 \%$ a $68 \%$ na matéria seca, respectivamente (GOODING, 1982). Porém seu teor de açúcares também aumenta com a maturação (Figura 2). Em comparação com outras gramíneas forrageiras, o valor nutritivo da cana-de-açúcar pouco se altera com a maturação, pois o aumento do teor de açúcares compensa a díminuição na digestibilidade da fração fibrosa. 


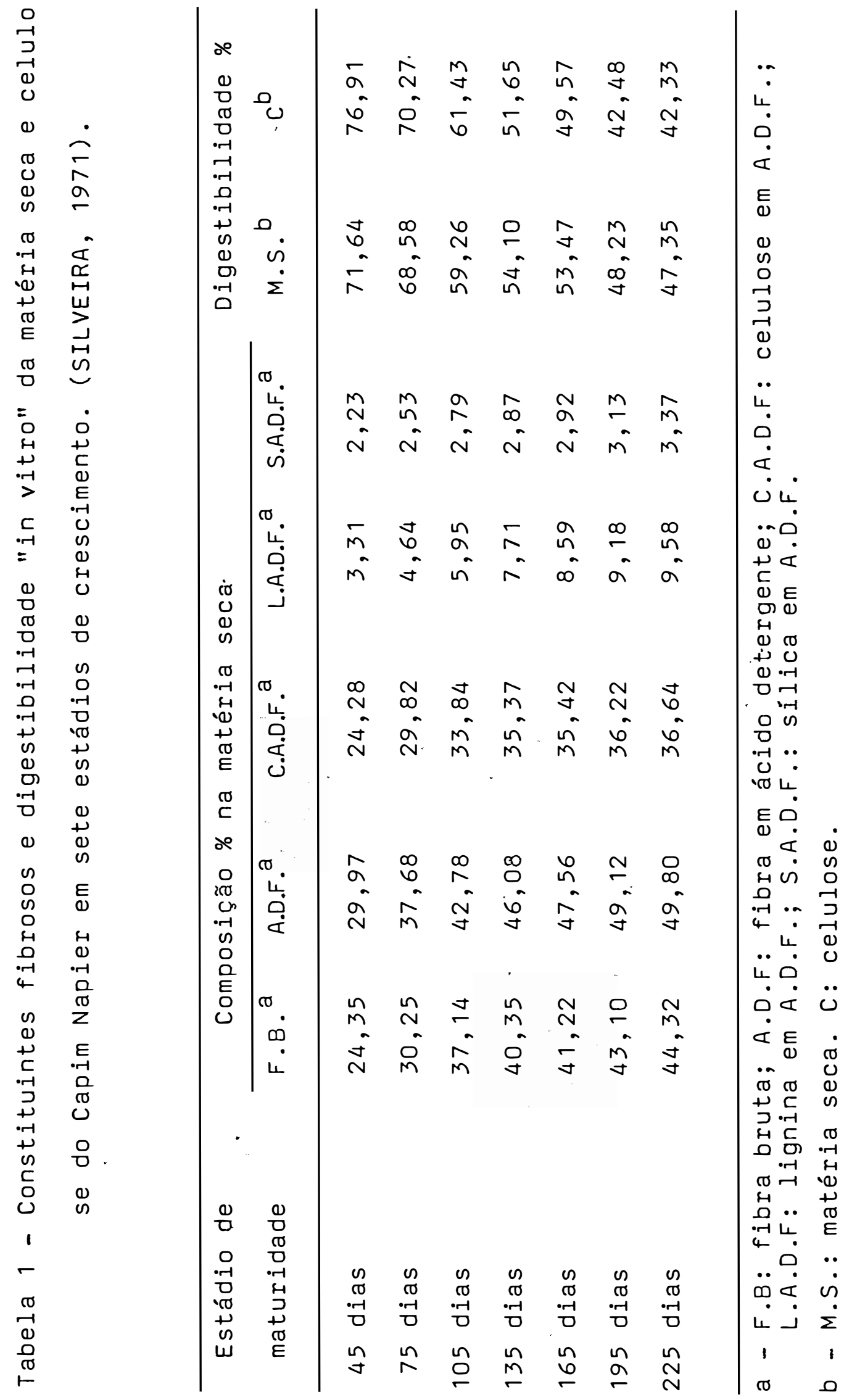




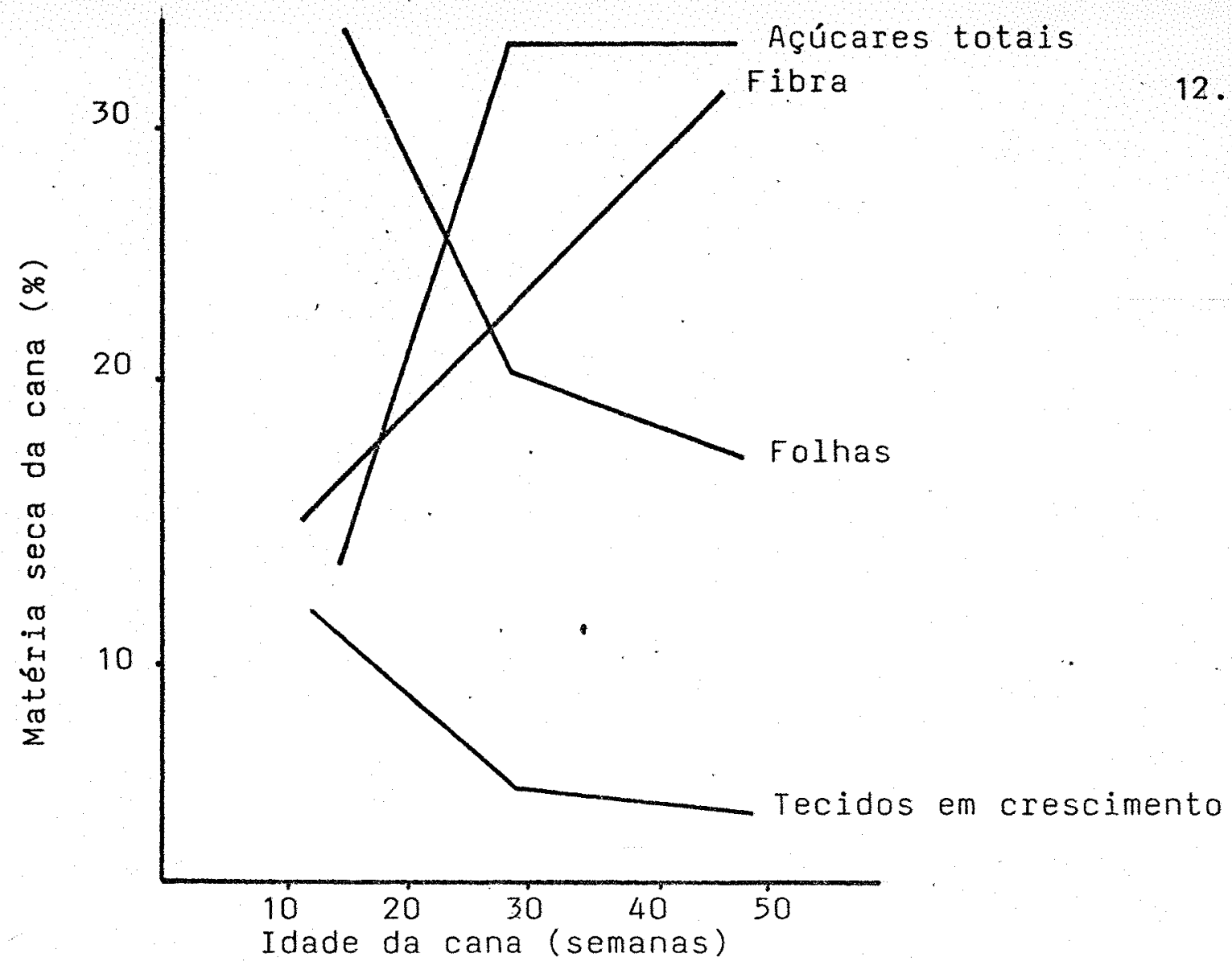

Figura 2 - Efeito da maturação sobre a MS de componentes da cana. (GOODING , 1982).

\subsubsection{Valor nutritivo do bagaço de cana}

$\mathrm{Na}$ indústria sucro-alcooleira, o processo de moagem da cana objetiva a máxima extração de conteúdo celular rico em açúcares. A cana é submetida à moagem e a sucessivas prensagens, visando a ruptura das células. Simultaneamente, so fre abundante lavagem para extração das substâncias solúveis li beradas. Nesse processo, obtem-se três produtos básicos: caldo, bagaço e bagacilho. o caldo é composto do conteúdo celular e da água de lavagem. O bagacilho é primeiramente extraido com o caldo de cana e depois retido em peneiras. É constitui- 
do de fragmentos da parede celular finamente moídos. 0 bagaço reúne fragmentos grosseiros da parede celular e pequena quantidade de conteúdo celular não extraído na moagem.

Cada tonelada de cana moída fornece cerca de $250 \mathrm{~kg}$ de bagaço com 50 \% de matéria seca. Entre 15 e 20\% do bagaço obtido não é utilizado nos processos de geração de energia e sobra nos páteos das indústrias.

o bagaço de cana, tal como obtido na indústria sucro-alcooleira apresenta reduzida digestibilidade e baixa densidade. Estes fatores restringem sua utilização para cerca de 30 \% da matéria seca das rações. Proporções mais elevadas causam retração no consumo e, consequentemente, um desempenho inferior. Em um experimento com vacas em lactą̧ão produzindo 20-25 kg leitẹ/dia, a produção foi mantida quando se forneceu apenas $22,5 \%$ de bagaço "in natura" na matéria seca (M.S.) de uma ração completa (RANDEL, 1970). Com vacas de menor produção - $15 \mathrm{~kg}$ leite/dia - foi possivel formular rações completas contendo $30-40 \%$ de bagaço "in natura" na M.S. (ROMAN-PON CE et alii, 1975). Para novilhas mestiças em crescimento, que apresentararn ganho de peso médio de 477 g/cabeça.dia, durante um ano, o bagaço "in natura" somente pode participar em 20,5 \% da M.S. da ração (JOSHI et alii, 1979). Trabalhando com bovinos confinados, PACOLA et alii (1977) forneceram ração 
completa com $40 \%$ de bagaço "in natura" na M.S., o que preju dicou o consumo e proporcionou ganhos de peso de apenas 650-720 g/cabeça.dia. Carneiros adultos castrados apresentaram consumo voluntário de 180,300 e $450 \mathrm{~g}$ de M.S. de bagaço "in natura" conforme receberam $100 \mathrm{~g}$ raspa de mandioca, $100 \mathrm{~g}$ fa relo de soja ou 200 g da mistura desses alimentos/dia (CAM POS et alii, 1977).

De um modo geral, esses pesquisadores utiliza ram o bagaço "in natura" apenas como fonte de fibra na formu lação de rações para ruminantes contendo elevada proporção de alimentos concentrados.

\subsection{Métodos de tratamento de forragens Iignificadas}

Processos de tratamento do bagaço de cana,bem como de outros alimentos volumosos grosseiros que se caracte rizam pelo elevado teor de fibra lignificada e pelo baixo teor de pro teína, como as palhadas de culturas, as cascas de cereais, palhas de ca pim e maravalha de madeira, vem sendo largamente estudados em vários países do mundo (JACKSON, 1978) visando à nutrição de ruminantes.

o objetivo dos tratamentos é promover a ruptü ra das complexás ligações químicas da lignina com a celulose e a hemicelulose. Devido a essas ligações, a celulose e a hemi celulose perdem suas propriedades higroscópicas e o acesso a esses polissacarideos, por parte dos microorganismos do rúmem 
e grandes moléculas-enzimas - fica prejudicado (GOSSELINK 1982). Foram desenvolvidos processos químicos, biológicos e físicos para o tratamento de residuos e subprodutos lignificados da agricultura. A eficiência desses processos de tratamento é variável, sendo que os trabalhos de pesquisa demonstram (JACKSON, 1978) que, no atual estágio de desenvolvi mento tecnológico, os processos físicos e químicos são mais efetivos que os biológicos.

\subsubsection{Tratamentos químicos}

Os tratamentos químicos, que utilizam substân cias alcalinizantes como a soda, a amônia e a uréia, são os de.uso mais difundido em paises da Europa e nos Estados Unidos (GOSSELINK, 1982). Promovem incrementos de 10 a 20 pontos percentuais na digestibilidade "in vitro" da MS (DIVMS) dos alimentos tratados (JACKSON, 1978) e requerem instalações, equipamentos e cuidados especiais. Existem processos de tratamento desenvolvidos há mais de 40 anos e que são efetivosem escala comercial. Em certas regiões, o custo dos produtos quí micos e o incremento que isso agrega ao custo final do mate rial tratado pode limitar a adoção dessa tecnologia. 
O desenvolvimento de processos biológicos para

o tratamento de volumosos grosseiros vem despertando grande in teresse nos últimos anos. Recentemente foram realizados traba lhos para avaliar a capacidade de bactérias (DESCHAMPS et alii, 1980) e de fungos (ZADRAZIL, 1980) em degradar lignina de madeira e de residuos da agricultura, visando a quebra do com plexo ligno-celulósico e aumento da digestibilidade desses materiais. O tempo de tratamento com fungos é longo, entre 1 e 3 meses, e o incremento na digestibilidade é muito variável em função do tipo de microorganismo, do resíduo volumoso, do tempo e temperatura de tratamento e da adição de suplementos à fermentação (ZADRAZIL e BRUNNERT, 1980). A pesquisa busca selecionar espécies de fungos que degradem seletivamente a lignina, não decompondo carboidratos que os próprios ruminantes são capazes de digerir. Não existem. ainda processos de tratamento biológico testados e aprovados em escala comercial.

\subsubsection{Tratamentos físicos}

Os processos de tratamento físico podem ser de três tipos: moagem, irradiação e aplicação de vapor d'água sob pressão. A moagem é utilizada visando maior consumo ou o processamento do material em "pellets". A irradiação objetiva promover a desagregação da fração fibrosa, incrementando a 
digestibilidade do material. O processo de tratamento físico com vapor sob pressão é o que apresenta maior potencial em fa ce dos resultados que já foram obtidos pela pesquisa (CAMPBELL et alii, 1973; PATE, 1982; RANGNEKAR et alii, 1982; MARCOS et alii, 1984). Este processo promove incrementos na digestibilidade dos volumosos grosseiros semelhantes aos proporciona dos pelos tratamentos químicos, mas rião envolve o uso de reagentes. Em outros paises, existem processos de tratamentocom vapor d'água sob pressão utilizados em escala comercial, no melhoramento do valor nutritivo de palhadas de culturas, resí duos de madeira e bagaço de cana (MACHADO, 1982). Este tipo de tratamento requer equipamentos especiais e disponibilidade de vapor d'água, o que implica em ser instalado anexo a plantas industriais acionadas por caldeiras, como as usinas e des tilarias.

\subsection{O processo de auto-hidrólise}

Entre os vários processos propostos para aumen tar o valor nutritivo de forragens lignificadas, destaca-se pe la simplicidade operacional o tratamento com pressão de vapor denominado de processo de auto-hidrólise. A disponibilidade de vapor sob pressão nas destilarias e usinas viabiliza este processo de tratamento dentro das indústrias. 
Tal processo foi descrito em 1931 por Mason (MA CHADO, 1982) e consiste em submeter o material lignocelulósico a elevadas pressões e temperaturas, durante um determinado periodo de tempo, seguido de uma descompressão repentina. Este tratamento promove profundas alterações na composição das fibras, resultando, quando utilizado sob condições específicas de pressão e tempo de tratamento, em significativo aumento na digestibilidade deste material tratado, por ruminantes.

MACHADO (1982) em sua revisão sobre aplicação de vapor e pressão em resíduos de madeira, seguida de descom pressão rápida, como pré-tratamento para a hidrólise enzimática da celulose, citou que a quebra do complexo lignina-po lissacarídeos ocorre através de dois efeitos distintos:

1. O primeiro efeito, variável com a temperatura e o tempo de tratamento, é a clivagem de grupos acetil da hemicelulose, o que proporciona um meio ácido e promove a hidrólise da hemicelulose, rompendo a estrutura da pare de celular . Esta etapa foi denominada de auto-hidrólise.

2. O segundo efeito é a "abertura" dos fragmentos de bagaço, devido à repentina expansão de 
vapor por efeito da descompressão rápida que ocorre ao final do tratamento. A água contida nos fragmentos de bagaço vaporiza-se subi tamente e sua expansão "rompe e afrouxa" a estrutura fibrosa da parede celular, pro movendo uma cominuição do material e aumen tando sua exposição ao ataque dos microorganismos do rúmem. Esta etapa foi denominada de descompressão rápida.

2.3.1. Efeitos do tratamento sobre o valor nutritivoda forragem

De acordo com a natureza do material lignocelulósico e com as caracteristicas dos equipamentos utilizados no processo, existem determinadas relações ideais entre a pressão e o tempo de tratamento, que proporcionam os maiores incrementos na taxa de digestibilidade "in vitro". (MARCos et alii,1984; HART et alii, 1981).

Os métodos de determinação da digestibilidade "in vitro" são iargamente adotados para avaliação dos efeitos desse tipo de tratamentos ( $\operatorname{ACCKSON}, 1978$ ). Em diversos trabalhos, amostras de bagaço de cana submetidas a tratamento com pressão de vapor, sob diferentes regimes de pressão e tempo de 
tratamento, apresentaram incremento na digestibilidade "in vi tro" de acordo com os dados da Tabela 2.

Foi observado que, para uma determinada pressão de trabalho, a digestibilidade "in vitro" aumenta com o tempo de tratamento, até um ponto de máximo, e depois decresce, com a aplicação de tempos maiores. Também foi observado que, quan to maior a pressão de trabalho, maior foi o incremento obtido na digestibilidade "in vitro" e isto aconteceu em um tempo me nor (TAYLOR e ESDALE, sem data), conforme mostra a Figura 3.

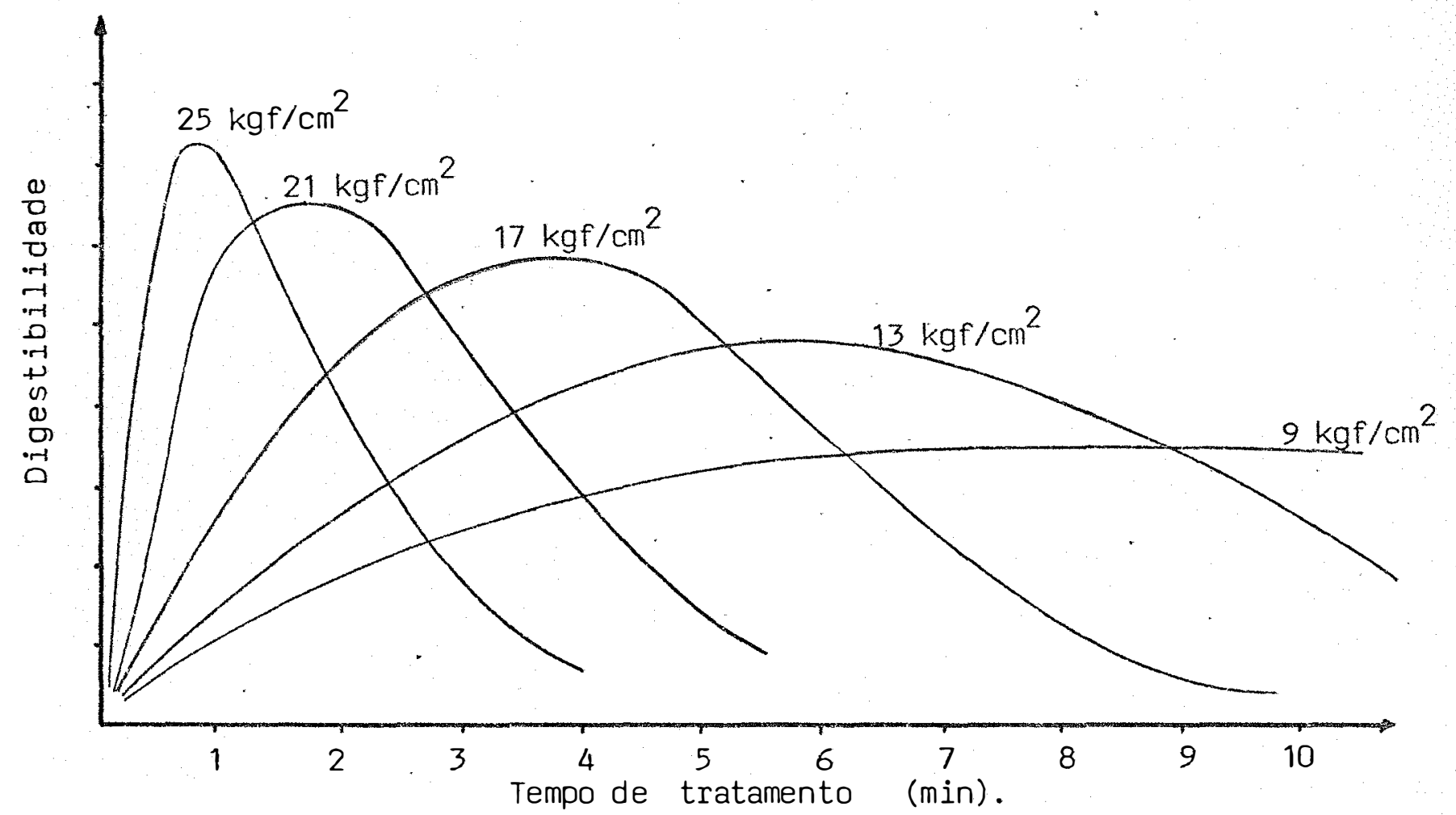

Figura 3 - Efeito da pressão e tempo de tratamento sobre a digestibilidade do bagaço de cana. (TAYLOR e ESDALE, sem data). 
Tabela 2 - Resultados de tratamentos com pressão de vapor so bre a digestibilidade "in vitro" da matéria seca (DIVMS) do bagaço de canà.

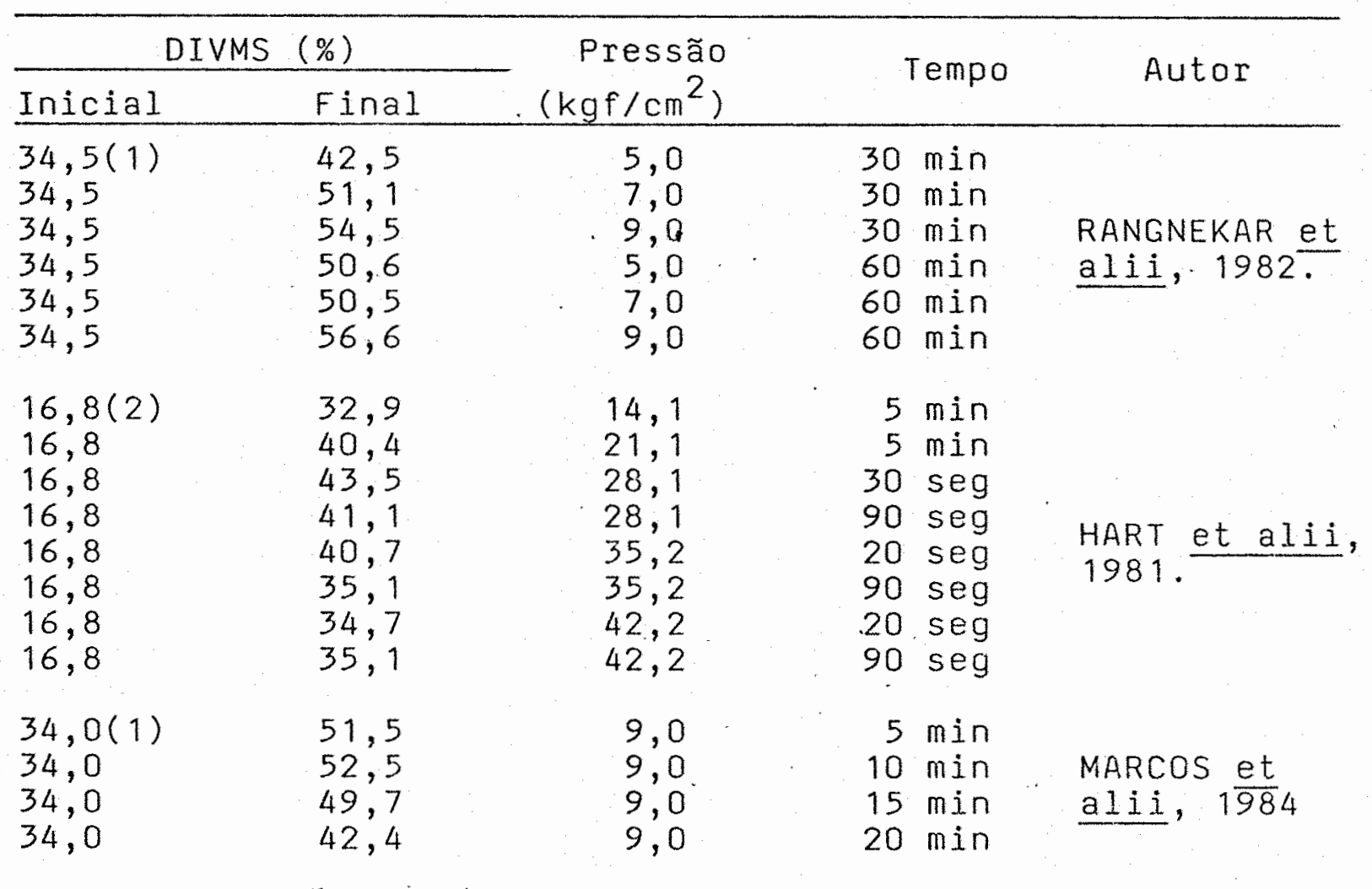

(1) Método de Tilley-Terry

(2) Método de Guggolz, modificado por Hart - determinação dos solúveis totais após digestão com celulase de Trichoderma viride por 16 horas.

Entre os efeitos do tratamento com pressão de vapor sobre os constituintes da parede celular, destaca-se o desaparecimento da hemicelulose (RANGNEKAR et alii, 1982). Os teores de lignina e de celulose pouco são afetados. Nos regimes de pressão e tempo de tratamento em que são obtidos incrementos máximos da digestibilidade "in vitro", o desaparecimento da hemicelulose é total. Sua degradação dá origem a ácido acético, 
pentoses, hexoses e furfural. A cor marrom e o cheiro característico do bagaço tratado se devem à formação dos chamados polímeros de Maillard, a partir da reação de condensação e polimerização entre substâncias nitrogenadas e os carboidratos prove nientes da degradação da hemicelulose,envolvendo também compos tos fenólicos,por copolimerização. (MACHADO, 1982;Van SOEST, 1982).

Com tempos de tratamento crescentes, há significa tivo incremento da fração extrato etéreo.MARCoS et alii (1984), utilizando pressão de $9 \mathrm{kgf} / \mathrm{cm}^{2}$ e tempos de $0,5,15$ e $20 \mathrm{minu}$ tos, determinaram teores de extrato etéreo de 2,5, 4,4, 6,7, 8,9 e $11,5 \%$, respectivamente.Atribuiram este fato à extração de compostos não lipidicos, provavelmente produtos fenólicos advindos da degradação de lignina.o potencial tóxico destes produtos fenólicos foi objeto de preocupação nas pesquisas conduzidas por HART et alii (1981) e CAMPBELL et alii (1973).

HART et alii (1981), trabalhando com palha de arroz, observaram que, no regime de pressão e tempo de tratamento $\left(21,1 \mathrm{kgf} / \mathrm{cm}^{2}\right.$ e 2 minutos) em que obtiveram o melhor resultado de digestibilidade "in vitro", o teor de fenóis passou de 0,43\% no material "in natura", para $1,64 \%$ no tratado. 
Possivelmente, com tempos de tratamento maiores, a degradação de lignina é mais extensa e a elevação dos niveis de fenóis deve prejudicar a atividade dos microorganismos do rúmem, o que eventualmente contribui para a reduça na digestibilidade "in vitro" observada em materiais submetidos a tratamentos mais longos.

Alguns trabalhos identificaram perdas de matéria seca, durante o tratamento (HART et alii 1981) da ordem de 5 a 16\%. Foi verificada a ocorrência de aumento no teor de umidade do material tratado, por condensação de vapor dentro do vaso de pressão (RANGNEKAR et alii 1980).

HART et alii (1981) estudaram os efeitos da adição de soluções de amônia, uréia e soda ao material lignocelulósico, antes de submetê-lo ao tratamento com vapor. Os aditivos nitrogenados não tiveram efeito sobre a digestibilidade "ịn vitro" das amostras tratadas. A retenção do nitrogê nio adicionado foi quase total até o nivel de 1,5\% de uréia so bre a matéria seca. Além desse valor, a retenção do excesso de nitrogênio foi pequena. A adição de soda nos níveis de $2 \%$ e $4 \%$ da matéria seca promoveu incremento da digestibilidade "in vitro", o que foi mais expressivo para a casca de arroz do que para o bagaço de cana. 


\subsubsection{Resultados com animais}

Trabalhos de avaliação do bagaço de cana e outros volumosos grosseiros tratados com pressão de vapor já foram realizados com animais, reunindo dados de metabolismo e de desempenho.

CAMPBELL et alii (1973) trataram bagaço de cana $\operatorname{com} 27,5 \mathrm{kgf} / \mathrm{cm}^{2}$ por 45 segundos e forneceram em rações comple tas para carneiros com peso médio de $47,2 \mathrm{~kg}$, em um ensaio de digestibilidade. 0 bagaço participou em $40 \%$ de matéria seca. Os resultados de consumo da matéria seca e digestibilidade da matéria orgânica foram $381,7, \quad 568,6$ e 571,9 g/cabeça.dia, e $61,4 \%, 72,0 \%$ e $67,5 \%$ para as rações com bagaço "in natura", ba gaço tratado e bagaço tratado-peletizado respectivamente. Neste trabalho foi observado um consumo inicial elevado das rações com bagaço tratado com uma sensivel redução após 3 dias de for necimento.

No entanto, GARRETT et alii (1981), trabalhando com ovinos pesando em média $26 \mathrm{~kg}$, obtiveram decréscimo na digestibilidade da matéria orgânica $(-6,3 \%)$ da celulose $(-9,7 \%)$, da proteína $(-26,4 \%)$ e da energia $(-8,1 \%)$, quando forneceram ração completa com $65 \%$ de palha de arroz tratada à $28 \mathrm{kgf} / \mathrm{cm}^{2}$ por 20 segundos, em relação a uma ração com mesmo nivel de palha de arroz sem tratamento. O tratamento da palha 
de arroz a $28 \mathrm{kgf} / \mathrm{cm}^{2}$ por 90 segundos também apresentou resul tados inferiores ao material não tratado. Obtiveram resultados positivos com relação à digestibilidade da matéria orgâni ca e da celulose, quando aplicaram à palha de arroz, $4 \%$ de so da ou $2,6 \% \mathrm{NH}_{3}$ e em seguida submeteram o material ao tratamen to de auto-hidrólise. Observaram, porém, que a utilização de palha de arroz tratada com pressão de vapor promoveu um decrés cimo sistemático na digestibilidade do nitrogênio de rações completas.

. PATE (1982) realizou experimentos de digestibi lidade, consumo e ganho de peso com bovinos recebendo rações à base de bagaço auto-hidrolisado. Trabalhou com novilhos pe sando em média $275 \mathrm{~kg}$, aos quais foram fornecidas rações completas com 56\% (na matéria seca) de bagaço tratado a $19,4 \mathrm{kgf} /$ $/ \mathrm{cm}^{2}$ por 4,3 minutos ou bagaço "in natura". Os resultados de digestibilidade da matéria seca das rações completas foram $65,8 \%$ e $60,7 \%$, respectivamente. No experimento de consumo ut lizando os mesmos animais e as mesmas condições de tratamento do bagaço, verificou que com níveis inferiores de bagaço trata do ( $32 \%$ da matéria seca), o consumo da ração foi maior. Após 20 dias de fornecimento obteve consumos de $6,8 \mathrm{~kg} \mathrm{MS} / \mathrm{cabeçadia}$ e $2,8 \mathrm{~kg}$ MS/cabeça.dia, para as rações completas com $32 \%$ e $56 \%$ de bagaço tratado. No experimento de ganho de peso com bo vinos confinados durante 91 dias, utilizou bagaço tratado a 
$20,4 \mathrm{kgf} / \mathrm{cm}^{2}$ por 2 minutos e bois de $360 \mathrm{~kg}$ de peso inicial Formulou rações com $0,14,30$ e 46 \% de bagaço tratado na matéria seca e obteve, respectivamente, consumo de 10,21, 10,93, 11,45 e 10,42 kg MS/cabeça.dia e ganhos de peso de 1,10, 1,23, 1,40 e $0,88 \mathrm{~kg} /$ cabeça.dia. 


\section{MATERIAIS E MÉTODOS}

o trabalho foi conduzido na Destilaria Alcidia S/A, em Teodoro Sampaio-SP, entre setembro de 1983 e maio de 1984 .

o tratamento do bagaço foi realizado em equipamento-protótipo desenvolvido pela Destilaria Alcidia S/A e construído em 1982 pela CALDEMA - Calderaria e Máquinas Agríco las Ltda., de Sertãozinho-SP.

o equipamento consiste de uma câmara de pressão em aço carbono com capacidade para 350 a $400 \mathrm{~kg}$ de bagaço "in natura", dotada de aberturas para carregamento e descarregamen to de bagaço, válvula de vapor com regulagem automática de pressão, válvula de descompressão rápida, termômetro e manômetro (ver Figura 4). O equipamento opera em regime de batelada e foi construido para trabalhar com pressão máxima de $21 \mathrm{kgf} /$ $/ \mathrm{cm}^{2}$, utilizando vapor super-aquecido proveniente das caldeiras da destilaria. 


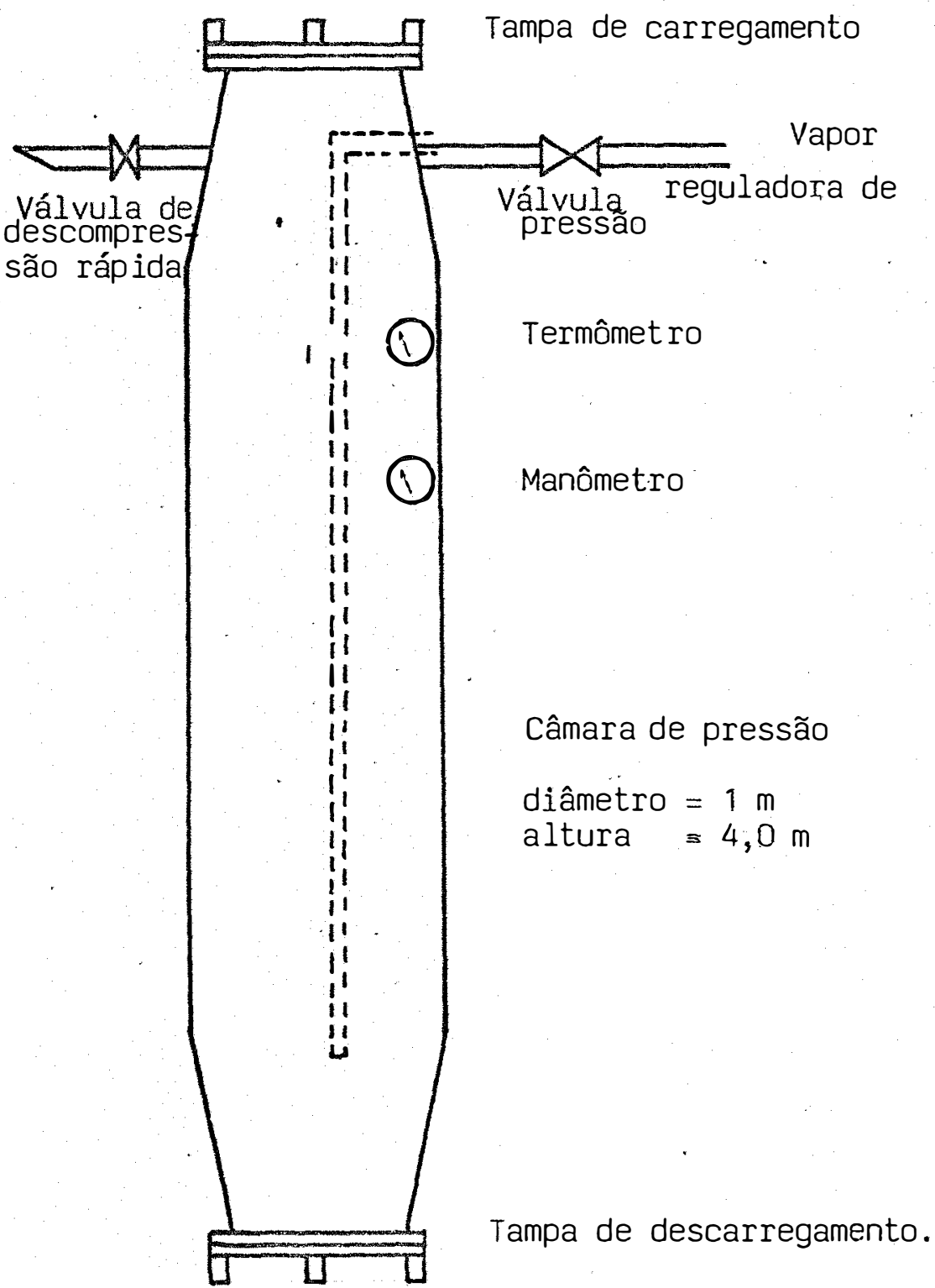

Figura 4 - 0 equipamento de auto hidrólise. (Cap.: $400 \mathrm{~kg}$ bagaço/batelada). 
3.1. Otimização e padronização do processo de tratamento

Foi seguida a recomendação de JACKSON (1978), de que a avaliação do efeito de tratamentos que visam melhorar o valor nutritivo de volumosos grosseiros, deve ser realizada através da comparação dos resultados de determinações da diges tibilidade "in vitro" dos materiais "in natura" e tratado.

Como o equipamento permite operar com diversas combinações de pressão e tempo de tratamento,procurou-se conhe cer quais combinações promoviam maior incremento na digestibilidade do bagáço de cana. MACHADO (1982) trabalhando com made ra de Eucalyptus paniculata observou que a temperatura e o tem po de tratamento influem na extensão da hidrólise da hemicelulose, durante a etapa de "auto-hidrólise", porém o equipamento utilizado neste trabalho não permitia controlar diretamente a temperatura, que variava entre $180^{\circ} \mathrm{C}$ e $210^{\circ} \mathrm{C}$, em função da com binação de pressão e tempo de tratamento adotada. Supõe-se que os efeitos da etapa de "descompressão rápida" sobre a digestibilidade dependam da pressão e da temperatura no interior da câmara e do teor de umidade do material, no momento da abertura da válvula de descompressão.

Foram realizados 24 tratamentos com diferentes combinações de pressão e tempo de tratamento. A pressão variou de 8 a $19 \mathrm{kgf} / \mathrm{cm}^{2}$ e o tempo de 2 a 14 minutos. O bagaço auto-hidrolisado (BAH) obtido em cada um desses tratamentos foi 
amostrado e submetido à determinação do $\mathrm{pH}$, matéria seca e di gestibilidade verdadeira "in vitro" da matéria seca (Van SOEST, 1982).

o objetivo foi obter informações que permitissem padronizar as condi.ções de pressão e tempo de tratamento para a obtenção de incrementos ótimos na digestibilidade do bagaço, durante a operação rotíneira do equipamento de auto-hidrólise da Destilaria Alcidia.

Várias amostras do bagaço auto-hidrolisado, ob tido após padronização do processo de tratamento, foram subme tidas a análise bromatológica e também foram feitas observa ções sobre a conservação do material tratado,em pilhas compac tadas e cobertas com lona plástica.

\subsection{Testes de conisumo}

Entre 13/10/83 e 20/12/83, foram realizados na Destilaria Alcidia, dois testes de consumo com bovinos confinados recebendo rações completas contendo bagaço auto-hidroli sado, tratado segundo as condições previamente padronizadas,a $17 \mathrm{kgf} / \mathrm{cm}^{2}$ por 5 minutos (BAH 17/5).

o primeiro teste teve o objetivo de verificar o efeito do nivel de bagaço auto-hidrolisado em rações comple 
tas sobre o consumo voluntário de novilhos confinados. Teve a duração de 39 dias e utilizou 24 novilhos anelorados, com ida de entre 18 e 30 meses, 260 a 320 kg de peso vivo, e que foram divididos aleatoriamente em 4 lotes referentes aos tratamentos, que apresentavam niveis crescentes de BAH 17/5 na matéria seca da ração, em substituição à cana picada, conforme discrimina a Tabela 3 .

Tabela 3 - Composição das rações completas do 10 teste de consumo (\% da matéria original).

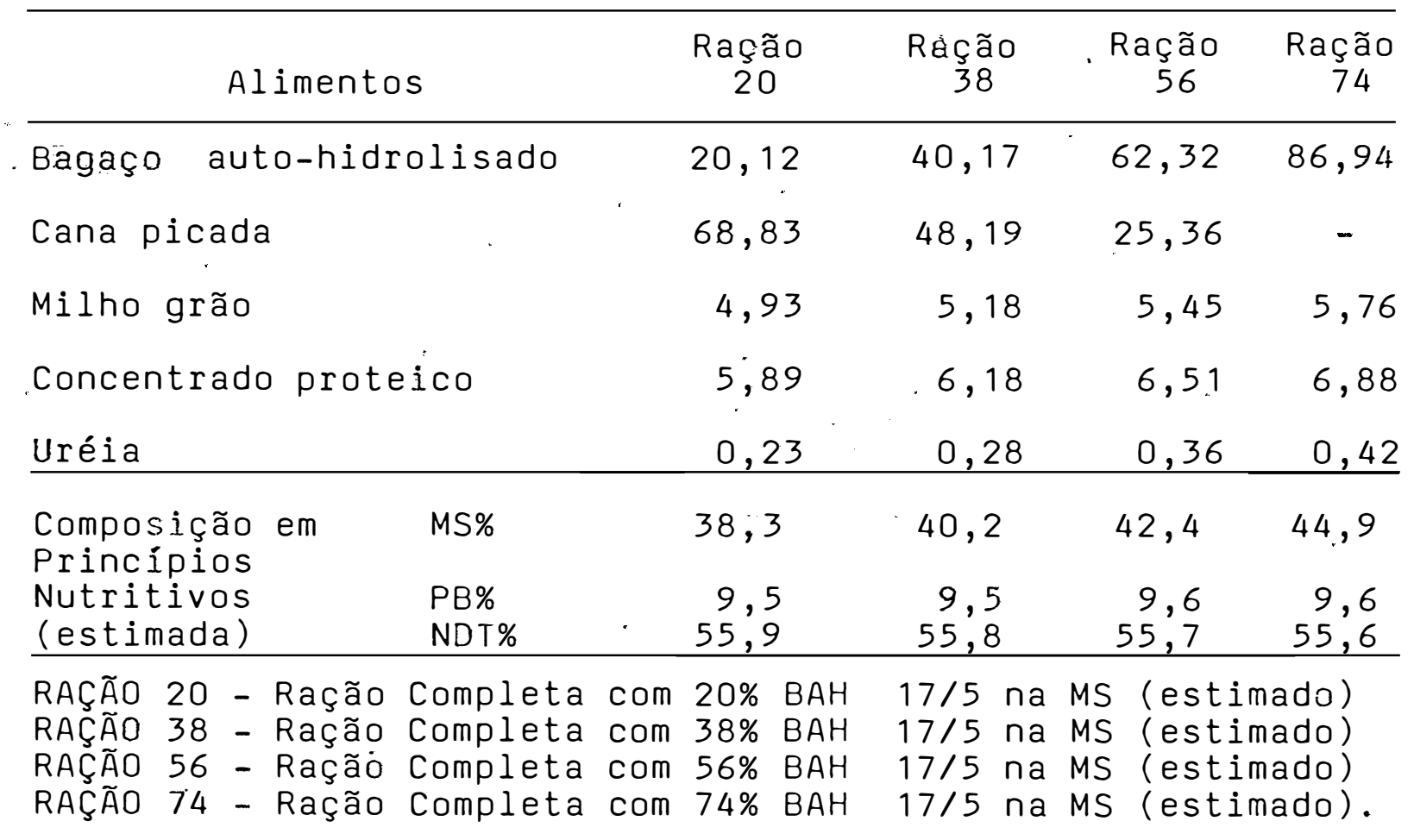


A alimentação foi em grupo. A ração fornecida para cada lote, bem como as respectivas sobras, foram pesadas diariamente durante os últimos 25 dias do teste, para determi nação do consumo. As rações completas foram amostradas sema nalmente e enviadas para anâlise.

O segundo teste teve o objetivo de verificar o efeito da adição de melaço como palatabilizante de uma ração completa com elevada proporção de BAH 17/5. Teve a duração de 28 dias e utilizou 20 novilhos provenientes do teste anterior, que foram divididos em dois lotes ao acaso e receberam rações completas com elevada proporção de BAH 17/5 na matéria seca, conforme apresentado na Tabela 4.

Foi registrado o consumo médio de cada lote, durante os últimos 20 dias do teste.

3.3. Experimento com bovinos confinados

O experimento foi conduzido na Destilaria Alci dia S/A, Teodoro Sampaio-SP, e teve a duração de 84 dias, de 09/02/84 a 03/0.5/84.

o objetivo foi verificar o efeito de proporções crescentes de bagaço auto-hidrolisado na dieta, em substituição à cana picada, sobre o desempenho de bovinos confinados. 
Tabela 4 - Composição das rações completas do 20 teste de consumo (em \% da matéria original).

Alimentos

Bagaço auto-hidrolisado

Milho grão

Concentrado proteico

Solução $40 \%$ melaço

Água

Uréia

Composição em

Principios

Nutritivos

(estimada)
Ração 74 M

$\begin{array}{rr}78,05 & 78,44 \\ 2,70 & 6,11 \\ 4,41 & 5,53\end{array}$

14,31

RAÇÃo 74 M - Ração completa com $74 \%$ de BAH $17 / 5$ na MS (estimado), com melaço.

RAÇÃo 74 SM - Ração completa com $74 \%$ de BAH $17 / 5$ na MS (estimado), sem melaço.

Também foram comparadas rações completas à base de bagaço auto-hidrolisado ou bagaço "in natura".

Foram utilizados 44 novilhos de corte entre 18 e 30 meses, de mesmo padrão racial (anelorados) e com peso médio inicial de $330 \mathrm{~kg}$. Na apartação, dia 08/02, os novilhos re ceberam vacina contra aftosa, vermífugo, implante de RALGRO e foram identificados com brincos plásticos. 
Os novilhos foram colocados nas quatro baias de confinamento, com piso de concreto, cocho coberto e com área de $52,5 \cdot \mathrm{m}^{2}$ cada $\left(4,8 \mathrm{~m}^{2} /\right.$ cabeça). Sobre o piso foi colocada uma camada fina de bagaço "in natura", que era substituida a cada dois dias, para a limpeza das baias.

Nos primeiros 12 dias, período de adaptação, os novilhos receberam a mesma alimentação, à base de cana e ponta de cana picadas. Nesse período, o bagaço auto-hidrolisado foi fornecido em proporções crescentes (20 até 50\% da MS da dieta) e foi feita adaptação à uréia.

No dia $21 / 02$, os novilhos foram pesados e separados ao acaso em lotes de 11 animais. Os tratamentos foram sorteados aos 4 lotes formados e iniciou-se o periodo de com paração, com 72 dias.

o delineamento estatistico foi de um experimento inteiramente casualizado, com 4 tratamentos e 11 repetições. Os quatro tratamentos foram:

(1) RAÇÃo 40 - ração completa com $40 \%$ de bagaço auto-hidrolisado na MS (estimado)

(2) RAÇÃO 50 - ração completa com 50\% de bagaço auto-hidrolisado na MS (estimado) 
(3) RAÇÃo 60 - ração completa com $60 \%$ de bagaço auto-hidroli sado na MS (estimado)

(4) RAÇÃO 60 T- ração completa com $60 \%$ de bagaço "in natura" na MS (estimado).

Dentro de cada tratamento, a alimentação foi em grupo, fornecida uma vez ao dia, pela manhã. Diariamente, logo antes do fornecimento das rações (Tabela 5), as sobras do dia anterior eram retiradas do cocho e pesadas. As quantidades for necidas eram reguladas para que as sobras ficassem entre 10 e $15 \%$, para garantir consumo à vontade por todos os animais do lote. Para cada ração, preparava-se uma solução de melaço e uréia (água + melaço + uréia) que era homogeneamente distribuí da, com regador, sobre uma pré-mistura dos outros componentes. A mineralização foi feita por adição de sal comum e complexomi neral diretamente nas rações completas e também através de cochos de sal instalados em cada baia de confinamento.

Os novilhos foram pesados individualmente no início do período de comparação e aos 30, 44, 58 e 72 dias de confinamento. As pesagens eram reaiizadas à 7:00 h, após jejum de alimentos de 14 horas. 
Tabela 5 - Composição das rações completas (\% da matéria original). do experimento com bovinos confinados.

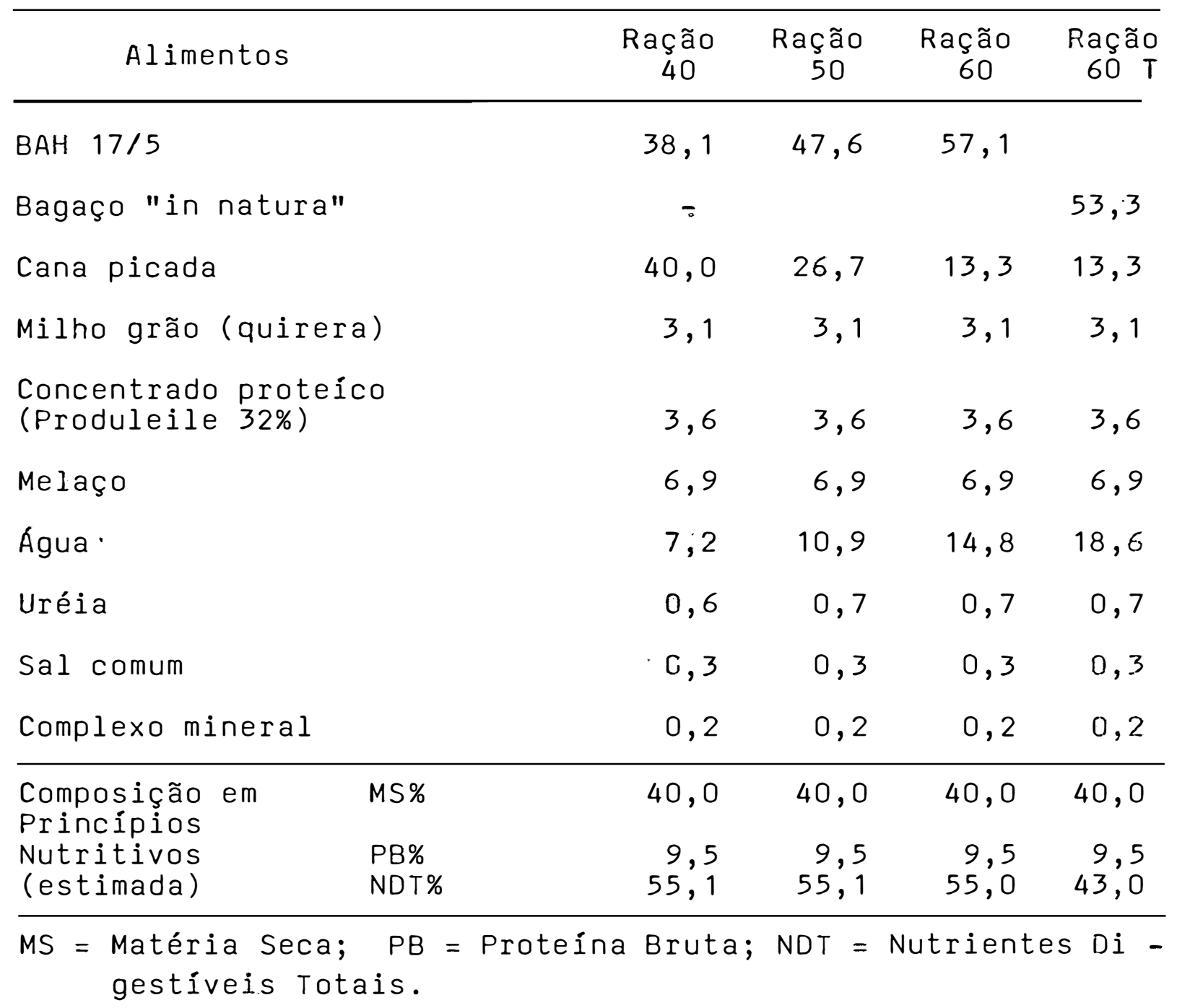

Os alimentos utilizados e as rações completas foram amostrados a cada 15 dias, para composição de amostras médias. Estas foram submetidas a análises bromatológicas segundo A.O.A.C. (1960) e Van SOEST e WINE (1968). 
4. RESULTADOS E DISCUSSÃO

\subsection{Padronização do processo de tratamento}

Os resultados de digestibilidade "in vitro" das amostras de bagaço auto-hidrolisado (BAH) tratadas com diferen tes combinações de pressão e tempo de tratamento estão na Tabe la 6 e Figura 5 .

Verificou-se que, quanto mais alta a pressão me nor é o tempo necessário para o tratamento, e mais elevados são os valores de digestibilidade atingidos.

Estes resultados estão de acordo com os apresen tados por TAYLOR e ESDALE (sem data) e por MARCOS et alii (1984).

0 incremento da digestibilidade foi de cerca de 30 pontos percentuais sobre a amostra de bagaço "in natura",pa ra as melhores combinações de pressão e tempo de tratamento.os 
38.

Tabela 6 - Digestibilidade verdadeira "in vitro" da matéria (DVIVMS) do bagaço auto-hidrolisado em função da pressão e do tempo de tratamento.

\begin{tabular}{|c|c|c|c|c|}
\hline $\begin{array}{r}A \\
(\mathrm{kgf} / \mathrm{cm}\end{array}$ & $\begin{array}{l}\text { Amostra } \\
\left.m^{2}\right) /(\min )\end{array}$ & $\mathrm{pH}$ & $\begin{array}{r}\text { MS } \\
(\%) \\
\end{array}$ & $\begin{array}{l}\text { DV I VMS } \\
(\%)\end{array}$ \\
\hline & $19 / 02$ & 3,3 & 38,58 & 77,47 \\
\hline & $17 / 14$ & 3,2 & 29,76 & 70,88 \\
\hline & $17 / 12$ & & 32,08 & 71,64 \\
\hline & $17 / 10$ & 3,3 & 36,26 & 73,67 \\
\hline & $17 / 08$ & & 40,96 & 73,01 \\
\hline & $17 / 06$ & 3,4 & 36,97 & 77,61 \\
\hline & $17 / 04$ & & 40,08 & 73,02 \\
\hline & $17 / 02$ & 3,7 & 39,56 & 68,71 \\
\hline & $14 / 14$ & & 36,90 & 68,94 \\
\hline & $14 / 10$ & 3,4 & 41,26 & 70,57 \\
\hline & $14 / 06$ & & 41,22 & 66,10 \\
\hline & $14 / 04$ & & 44,81 & 59,79 \\
\hline & $14 / 02$ & & 44,97 & 57,00 \\
\hline & $11 / 14$ & 3,5 & 36,05 & 75,59 \\
\hline & $11 / 10$ & 3,6 & 39,39 & 73,14 \\
\hline & $11 / 04$ & & $42 ; 22$ & 61,02 \\
\hline & $11 / 02$ & & 46,07 & 58,27 \\
\hline & $08 / 14$ & 3,8 & 36,69 & 71,64 \\
\hline & $08 / 10$ & 3,8 & 39,54 & 63,43 \\
\hline & $08 / 06$ & & 37,67 & 59,17 \\
\hline & $08 / 04$ & & 43,21 & 56,92 \\
\hline & $08 / 02$ & & 42,57 & 54,91 \\
\hline & $00 / 00$ & 5,5 & 44,05 & 46,41 \\
\hline Padrão & Bagaço & & 48,31 & 47,85 \\
\hline Padrão & Napier & & & 77,85 \\
\hline Bagacilt & ho $17 / 5$ & 3,7 & 28,83 & 64,24 \\
\hline
\end{tabular}


$38 a$.

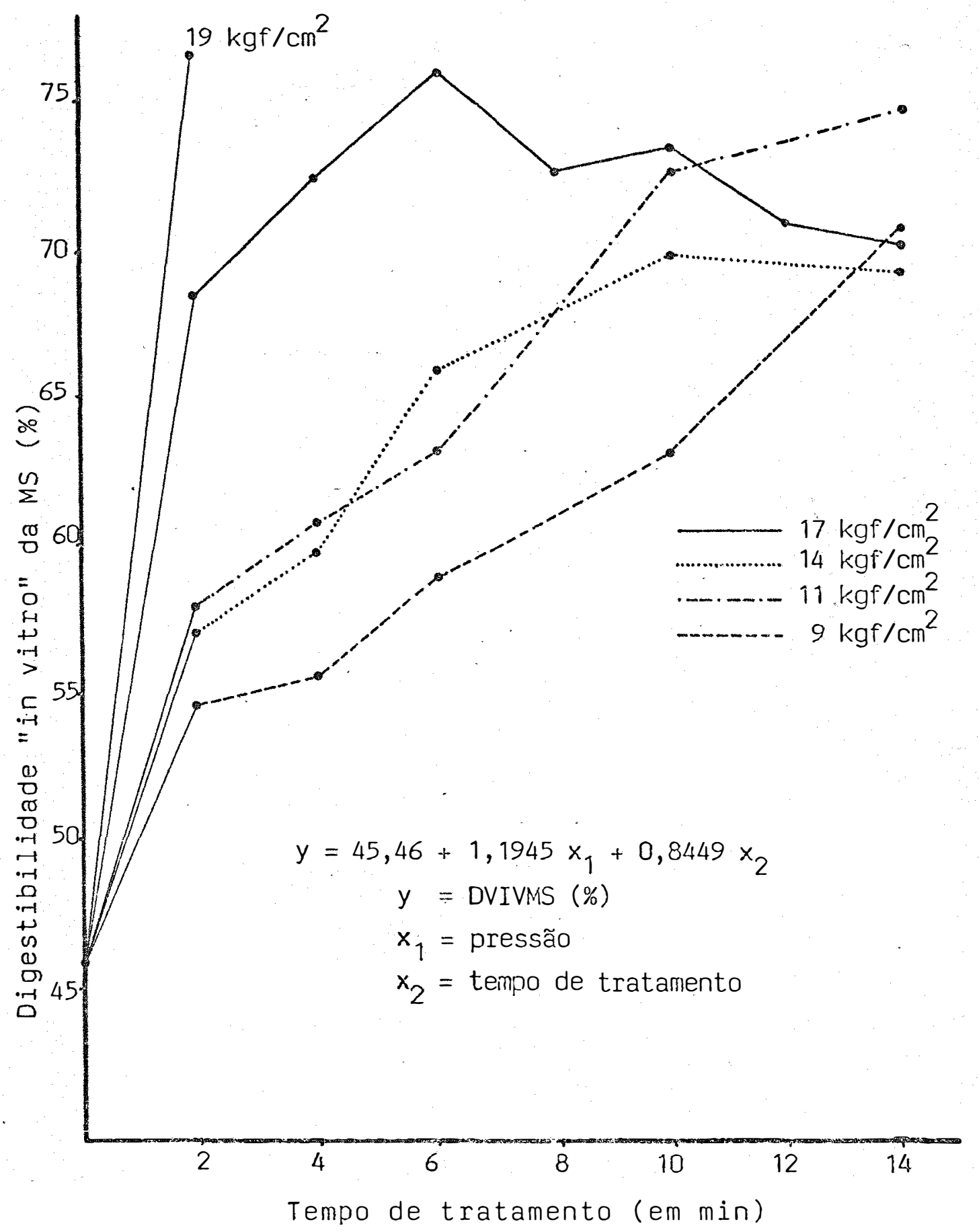

Figura 5 - Digestibilidade verdadeira "in vitro" da matéria seca (DVIVMS) do bagaço hidrolisado em função da pressão e do tempo de tratamento. 
melhores resultados foram comparáveis ao do padrão adotado no Laboratório de Bromatologia da ESALQ, que é uma amostra de fo Ihas de capim elefante (Pennisetun purpureum, Schum) com 20 dias de crescimento, e atingiram cerca de $77 \%$ de digestibilii: dade.

0 método de digęstibilidade "in vitro" utiliza do estima a digestibilidade verdadeira dos alimentos. Para ob tenção do valor de digestibilidade aparente, os resultados de vem ser subtraídos de 12,9 pontos percentuais (Van SOEST,1982).

Optou-se por padronizar o tratamento com pressão de $17 \mathrm{kgf/ \textrm {cm } ^ { 2 }}$ e tempo de 5 minutos; pois esta combinação situa-se na área ótima do gráfico obtido. 0 bagaço auto-hi drolisado assim obtido foi denominado de BAH 17/5 (Tabela 7 ). Não foi adotada uma pressão mais elevada, pois as caldeiras da destilaria não poderiam proporcioná-la permanentemente e isto prejudicaria a produção padronizada do bagaço auto-hidrolisado.

A Tabela 8 apresenta os resultados médios de diversas análises do BAH $17 / 5$ e do bagaço "in natura". Observe-se que com o tratamento ocorre diminuição no teor de NDF de vido ao desaparecimento da hemicelulose, ligeiro acréscimo no teor de extrato etéreo (conforme resultados de MARCos et alii. 
Tabela 7 - Tratamento padronizado do bagaço de ćana com aplicação de vapor d'água sob pressão de $17 \mathrm{kgf} / \mathrm{cm}^{2}$ durante 5 minutos (obtenção do $\mathrm{BAH}$ 17/5).

\begin{tabular}{|c|c|c|c|}
\hline Fase do processo & Minuto & $\begin{array}{c}\text { Temperatura } \\
\left({ }^{\circ} \mathrm{C}\right)\end{array}$ & $\begin{array}{c}\text { Pressão } \\
\left(\mathrm{kgf} / \mathrm{cm}^{2}\right)\end{array}$ \\
\hline \multirow[t]{3}{*}{ Inicio do carregamento } & 00 & 90 & 0 \\
\hline & 04 & 80 & 0 \\
\hline & 07 & 70 & 0 \\
\hline Fim do carregamento & 09 & 80 & 0 \\
\hline \multirow{2}{*}{ Início Injeção de Vapor } & 10 & 95 & 0 \\
\hline & 11 & 140 & 11 \\
\hline \multirow[t]{4}{*}{ Início da contagem } & 12 & 175 & 16,5 \\
\hline & 14 & 200 & 17,0 \\
\hline & 15 & 205 & 17,0 \\
\hline & 16 & 210 & 17,5 \\
\hline \multicolumn{4}{|l|}{ Final da contagem - } \\
\hline \multirow[t]{2}{*}{ Liberação do vapor } & 17 & 210 & 17,5 \\
\hline & 18 & 165 & 0 \\
\hline Inicio da descarga & 21 & 155 & 0 \\
\hline Final da descarga & 24 & 155 & 0 \\
\hline
\end{tabular}


1984), manutenção dos níveis de celulose, lignina e proteína, redução da fibra bruta e incremento no teor de extratiıo não nitrogenado. Além disso ocorre diminuição do teor de matéria seca e aumento da acidez do material tratado. Há um incremento de 84 \% na digestibilidade, com relação ao bagaço "in natu ra".

Tabela 8 - Resultados médios de análises bromatológicas do BAH. $17 / 5$ e do bagaço "in natura".

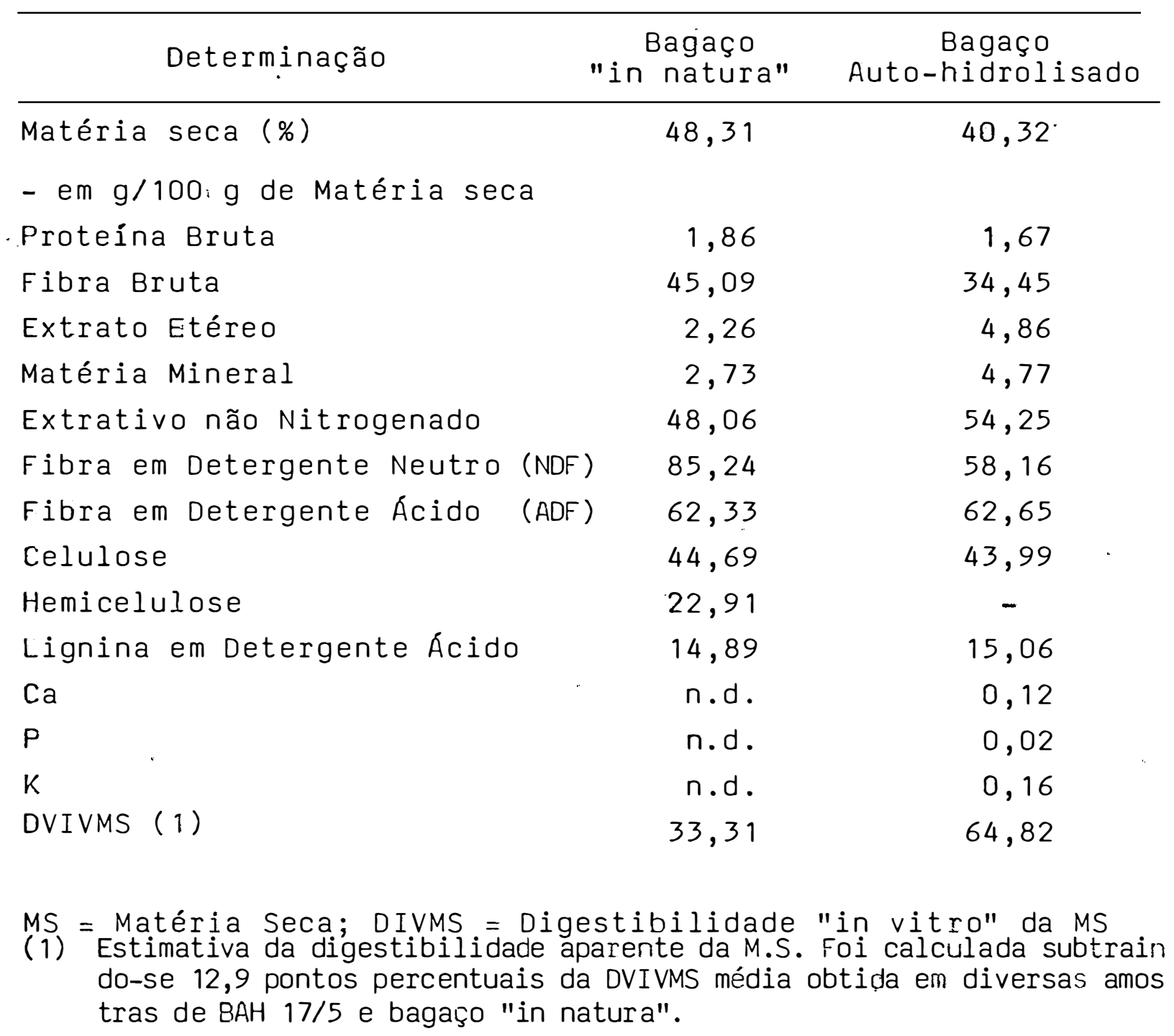


o bagaço auto-hidrolisado apresenta coloração marrom, densidade 2 a 3 vezes superior à do bagaço "in natura", maior friabilidade e textura macia. É um material rela tivamente estável, provavelmente devido à acidez, que pode ser armazenado em pilhas compactadas e cobertas por lona plás tica, na forma de um silo de superficie. Foi notado ataque de fungos na camada superficial da pilha $(20$ a $30 \mathrm{~cm}$ ) e, durante todo o periodo de armazenamento, de 8 meses, a temperatura no seu interior permaneceu elevada, entre 40 e $50^{\circ} \mathrm{C}$. É ne cessário desenvolver mais estudos sobre a conservação do bagaço auto-hidrolisado.

\subsection{Testes de consumo}

No primeiro teste determinou-se uma regressão significativa entre proporção de $B A H 17 / 5$ na dieta e consumo voluntário de matéria seca (Figura 6). No segundo teste,porém, o consumo de rações com elevada proporção de BAH 17/5 foi satisfatório, independente da adição de palatabilizante (Tabela 9). Como foram utilizados novilhos provenientes do teste de consumo anterior, inferiu-se que a adaptação a dietas contendo bagaço auto-hidrolisado é lenta, decorrendo 20 a $30^{\circ}$ dias até a estabilização do consumo. 


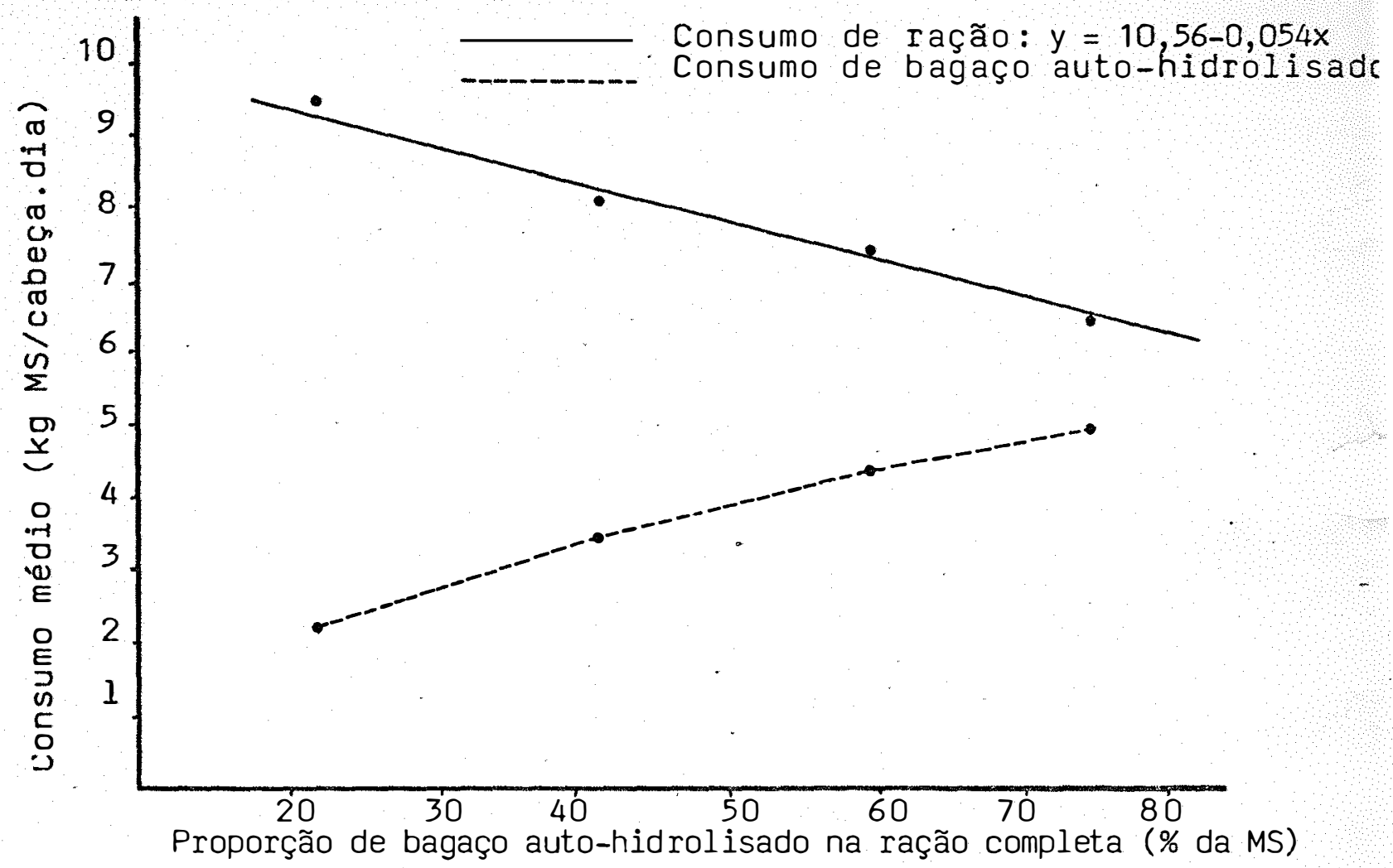

Figura 6 - Consumo em função da proporção de BAH 17/5 na ração completa.

Tabela 9 - Consumo de matéria seca como porcentagem do peso vi vo de bovinos alimentados com rações completas à base de BAH $17 / 5$.

\begin{tabular}{|c|c|c|c|c|}
\hline \multirow{2}{*}{ Tratamento } & \multicolumn{2}{|c|}{ Consumo } & \multirow{2}{*}{$\begin{array}{c}\text { PV } \\
\text { Médio } \\
(\mathrm{kg})\end{array}$} & \multirow{2}{*}{$\begin{array}{l}\text { Cons.propor } \\
\text { cional } \\
(\mathrm{kg} \mathrm{MS} / 100 \mathrm{~kg} \\
\text { PV.dia) }\end{array}$} \\
\hline & $\begin{array}{l}\text { kg MO/ } \\
\text { / cab.dia }\end{array}$ & $\begin{array}{l}\text { Kg MS/ } \\
\text { /cab.dia }\end{array}$ & & \\
\hline Ração 74 M & 18,60 & 9,38 & 323,05 & 2,90 \\
\hline Ração 74 SM & 16,36 & 8,80 & 316,30 & 2,78 \\
\hline
\end{tabular}


Após esse período, o BAH, mesmo em elevada prọ porção na dieta, aparentemente não prejudicou o consumo volun tário das rações completas. O consumo de BAH $17 / 5$ atingiu niveis superiores a $2 \mathrm{~kg} \mathrm{MS/100} \mathrm{kg} \mathrm{PV,} \mathrm{quando} \mathrm{fornecido} \mathrm{na} \mathrm{pro-}$ porção de $74 \%$ da matéria seca da dieta.

\subsection{Experimento com bovinos confinados}

A Tabela 10 apresenta os resultados das análises bromatológicas dos alimentos utilizados no preparo das ra ções completas. O bagaço "in natura" foi retirado da pilha de sobra de bagaço, a mais de $2 \mathrm{~m}$ de profundidade, e apresenta va-se com caracteristicas de ensilagem. Observe-se que o baga ço "in natura" apresenta um teor de $24 \%$ de hemicelulose, que desaparece no bagaço auto-hidrolisado. o teor de proteína bru ta do melaço foi superior ao esperado.

Com base nesses resultados de análise, pudemos calcular a porcentagem real de cada alimento na matéria seca das rações completas (Tabela 11). Verifica-se que as porcenta gens de bagaço na MS das rações resultaram muito próximas do

planejado, indicando que os teores de umidade considerados pa ra os alimentos no balanceamento das rações foram adequados. 


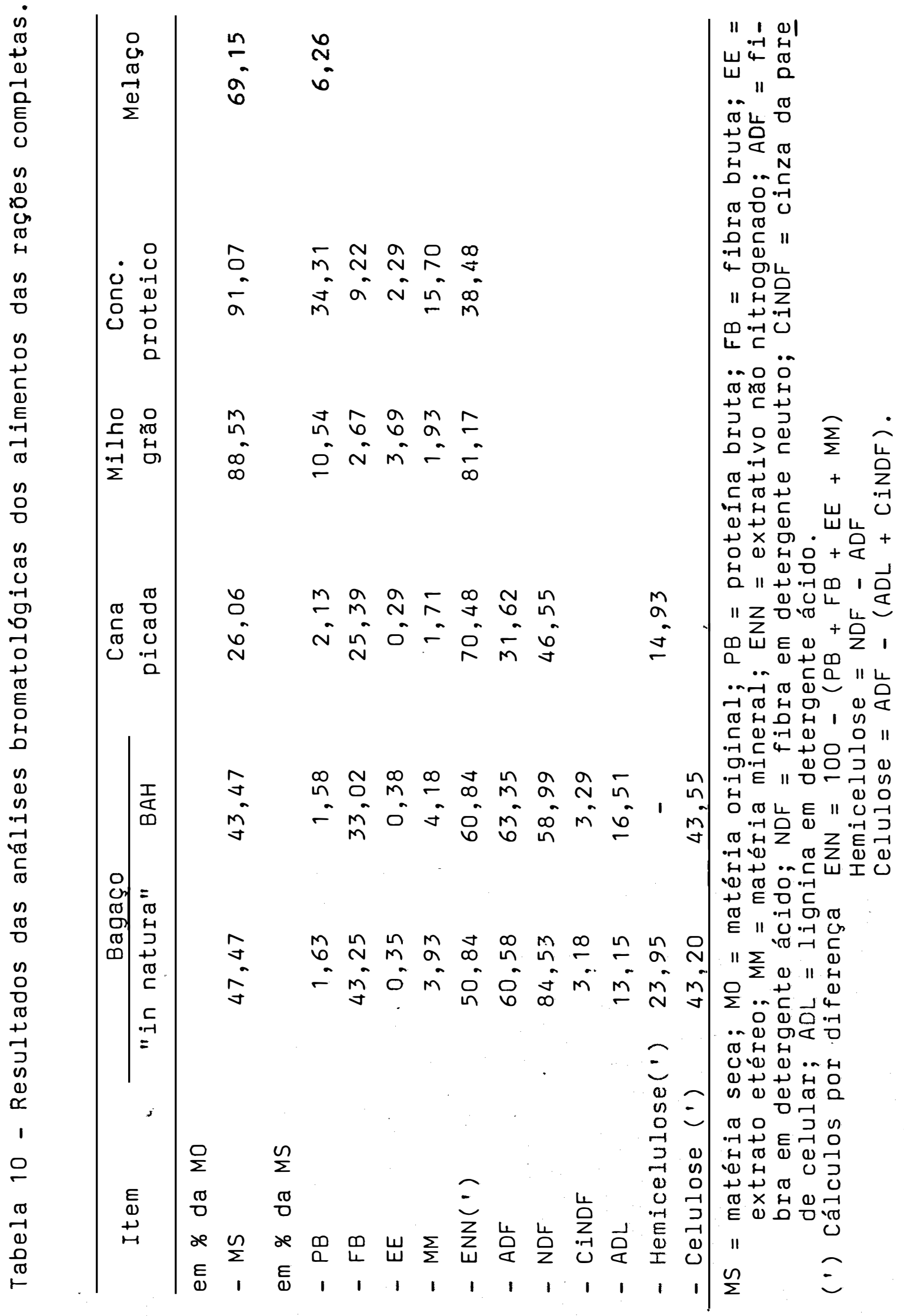


46.

Tabela 11 - Porcentagem dos alimentos na matéria seca das rações completas à base de BAH $17 / 5$ ou bagaço "in natura".

\begin{tabular}{lcccc}
\hline Alimento & Ração 40 & Ração 50 & Ração 60 & Ração 60 T \\
\hline BAH $17 / 5$ & 42,6 & 52,2 & 61,6 & - \\
Bagaço "in natura" & - & - & - & 62,1 \\
Cana picada & 26,8 & 17,5 & 8,6 & 8,5 \\
Milho grão & 7,1 & 6,9 & 6,8 & 6,7 \\
Conc.proteico & 8,4 & 8,3 & 8,1 & 8,1 \\
Melaço & 12,3 & 12,0 & 11,8 & 11,7 \\
Uréia & 1,5 & 1,8 & 1,8 & 1,7 \\
Sal comum & 0,8 & 0,8 & 0,8 & 0,7 \\
Complexo mineral & 0,5 & 0,5 & 0,5 & 0,5 \\
\hline
\end{tabular}

As quatro rações completas apresentaram composições semelhantes quanto aos principios nutritivos analisados, conforme atestam os resultados da Tabela 12 .

Observe-se que, à medida que aumentou a proporção de bagaço auto-hidrolisado, o teor de hemicelulose diminuiu. Os teores de lignina foram muito próximos em todas as rações.os teores de MM foram elevados, indicando que pode ter havido algu ma contaminação com terra durante o transporte e armazenamento do bagaço. Além disso, o sal comum e complexo mineral foram adi. cionados às rações completas. A CiNDF representa a cinza insolú 
Tabela 12 - Resultados das análises bromatológicas das rações completas à base de BAH 17/5 ou bagaço "in natura".

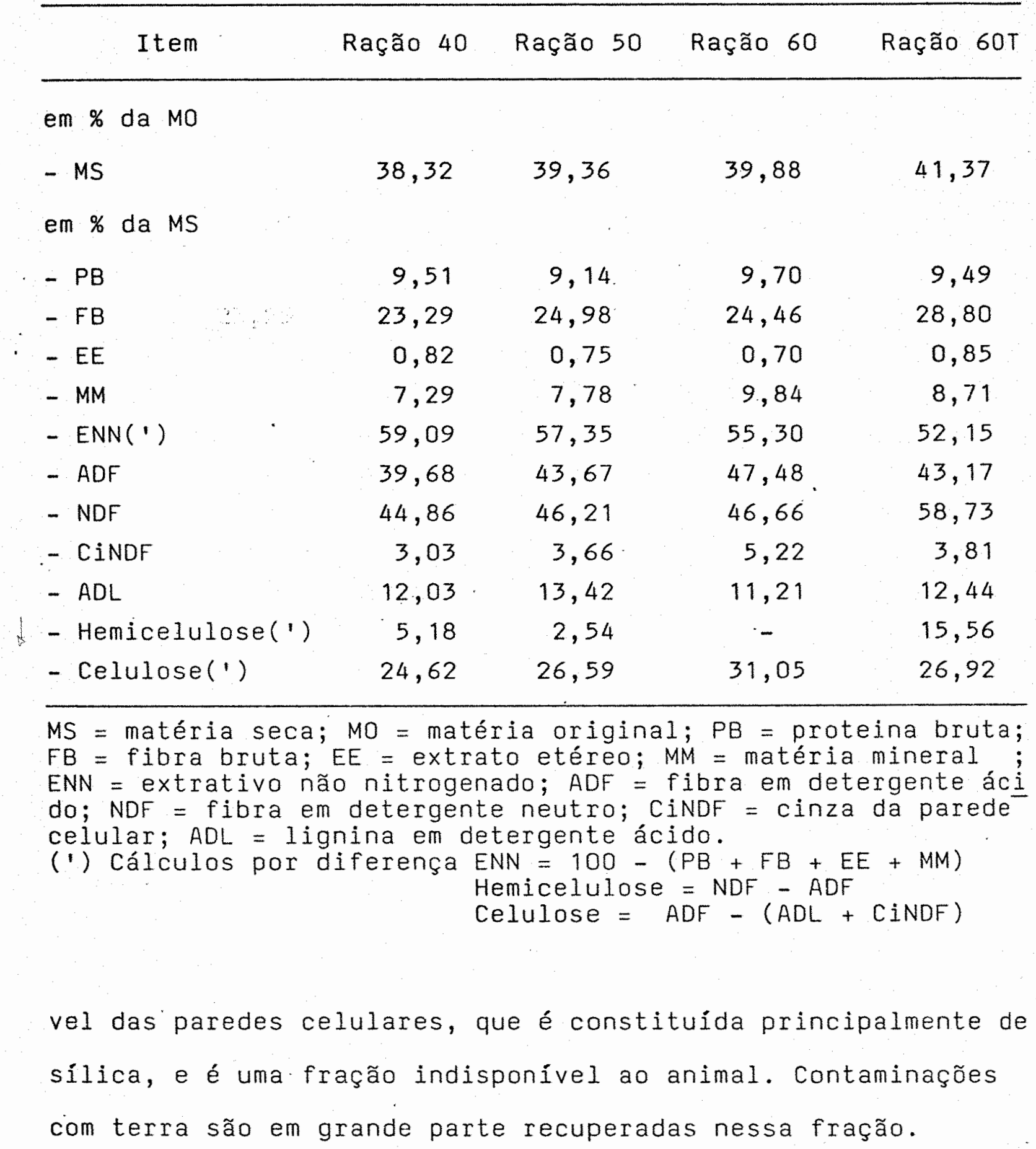


A Tabela 13 e a Figura 7 apresentam a evolução do consumo das rações durante o experimento. Observa-se que as curvas referentes às rações com bagaço auto-hidrolisado são muito próximas, à exceção das primeiras 3 semanas, em que houve um consumo menor da Ração 60 . Daí para frente, o consumo dessas rações aproximou-se e tendeu a estabilizar por volta dos $11,4 \mathrm{~kg} M S / c a b . d i a$. Isso nos sugere que ocor re uma adaptação gradativa dos animais a dietas com elevados niveis de bagaço auto-hidrolisado e que essa adaptação leva cerca de 3 semanas. Após esse período, independente das pro porções de cana picada e bagaço auto-hidrolisado, os consumos dessas três rações completas (Rações 40,50 e 60 ) foram eleva dos e semelhantes. A Ração $60 \mathrm{~T}$, com bagaço "in natura", teve seu consumo estabilizado em 63 \% das outras rações.

Tabela 13 - Consumo médio diário das rações completas (kg/cab. .dia) à base de BAH 17/.5 ou bagaço "in natura".

\begin{tabular}{|c|c|c|c|c|}
\hline Período & Ração 40 & Ração 50 & Ração 60 & Ração $60 \mathrm{~T}$ \\
\hline $\begin{array}{l}21 / 02 \text { a } 03 / 05 \\
\text { (período de com } \\
\text { paração) }\end{array}$ & $\begin{array}{l}25,88 \\
(9,92) *\end{array}$ & $\begin{array}{l}25,41 \\
(10,00)\end{array}$ & $\begin{array}{c}25,40 \\
(10,13)\end{array}$ & $\begin{array}{l}16,21 \\
(6,71)\end{array}$ \\
\hline $\begin{array}{l}22 / 03 \text { a } 03 / 05 \\
\text { (após estabili- } \\
\text { zação do consu- } \\
\text { mo) }\end{array}$ & $\begin{array}{r}29,16 \\
(11,17) \\
\end{array}$ & $\begin{array}{l}28,85 \\
(11,36)\end{array}$ & $\begin{array}{c}29,52 \\
(11,77)\end{array}$ & $\begin{array}{l}17,39 \\
(7,19)\end{array}$ \\
\hline
\end{tabular}


49.

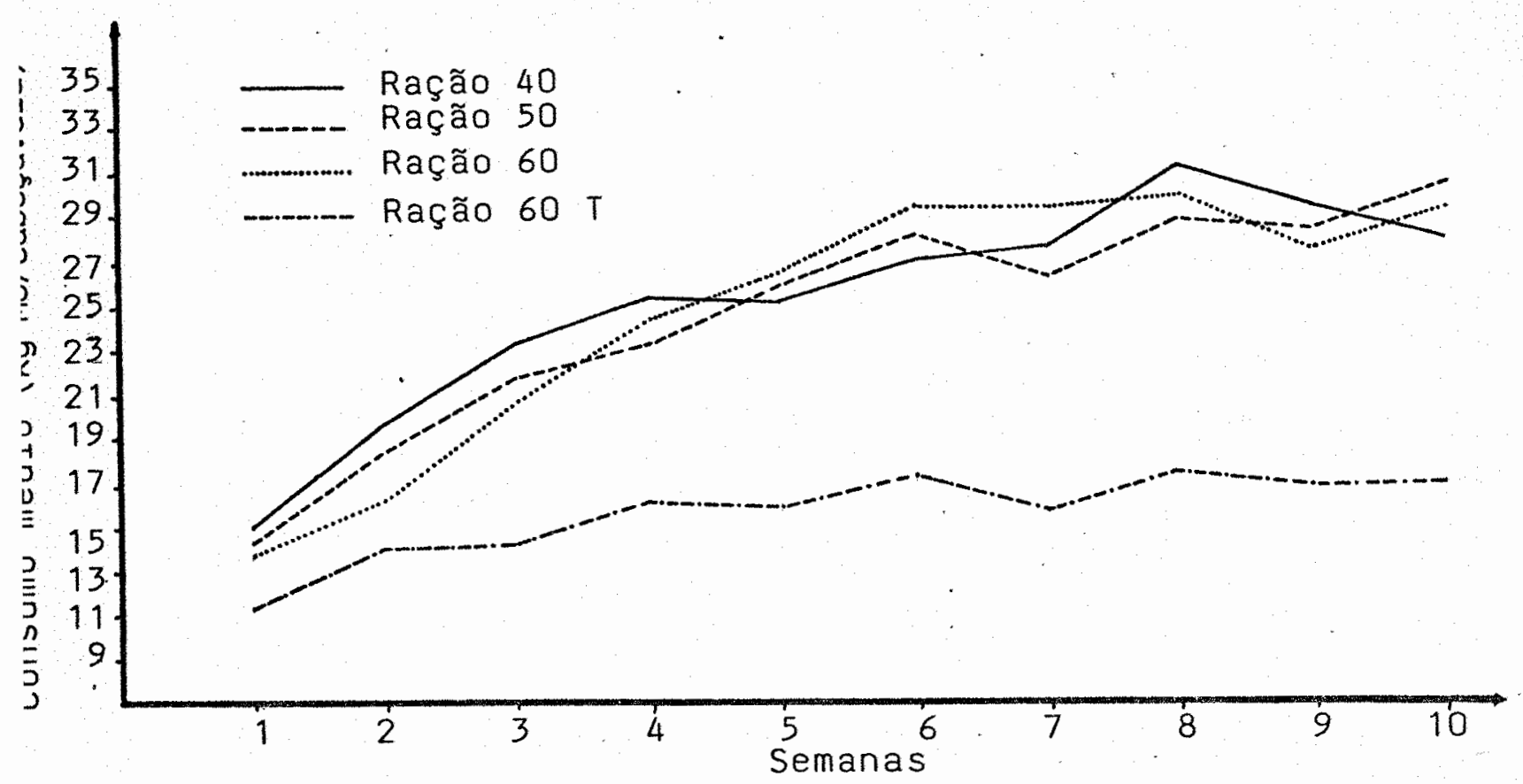
Figura 7 - Evolução do consumo das rações completas à base de
BAH $17 / 5$ ou bagaço "in natura".

A Tabela 14 apresenta os resultados de três pesagens: (a) pesagem inicial em $21 / 02$, (b) pesagem após estabilização do consumo em $22 / 03$ e (c) pesagem final em 03/05.

Foram calculados os ganhos de peso médios diários durante os 72 dias do periodo de comparação e durante os últimos 42 dias do experimento (consumo estabilizado). Os resultados estão na Tabela 15 . 
Tabela 14 - Resultados das pesagens dos bovinos alimentados com as rações completas à base de $\mathrm{BAH} 17 / 5$ ou bagaço "in natura".

\begin{tabular}{lccc}
\hline \multirow{2}{*}{ Tratamento } & \multicolumn{4}{c}{ Pesagens } \\
\cline { 2 - 4 } & $21 / 02$ & $22 / 03$ & $($ (a) \\
\hline Ração 40 & $324,55 \pm 9,81$ & $352,45 \pm 11,74$ & $393,64 \pm 12,03$ \\
Ração 50 & $329,55 \pm 8,03$ & $349,18 \pm 8,84$ & $388,27^{+} 9,82$ \\
Ração 60 & $332,00 \pm 9,86$ & $346,09 \pm 9,24$ & $394,82 \pm 9,85$ \\
Ração 60 & $333,00 \pm 7,93$ & $357,64 \pm 7,70$ & $383,36 \pm 8,63$ \\
\hline
\end{tabular}

Tabela 15 - Resultados de ganho de peso dos bovinos alimentados com as rações completas à base de BAH $17 / 5$ ou bagaço "in natura".

\begin{tabular}{|c|c|c|c|}
\hline \multirow{2}{*}{\multicolumn{2}{|c|}{ Tratamento }} & \multicolumn{2}{|c|}{ GPD (kg/cab:dia) } \\
\hline & & $\begin{array}{l}\text { entre } \\
21 / 02 \text { e } 03 / 05^{(*)}\end{array}$ & $\begin{array}{l}\text { entre } \\
22 / 03 \text { e } 03 / 05^{(*)}\end{array}$ \\
\hline Ração 4 & 40 & $0,960 \pm 0,058 a$ & $0,981 \pm 0,044 b$ \\
\hline Ração 5 & & $0,816 \pm 0,045 a b$ & $0,931 \pm 0,046 b$ \\
\hline Ração 6 & & $0,872 \pm 0,044 a$ & $1,160 \pm 0,037 a$ \\
\hline Ração 6 & $60 \mathrm{~T}$ & $0,699 \pm 0,042 b$ & $0,613 \pm 0,041 \cdot c$ \\
\hline \multicolumn{4}{|c|}{ 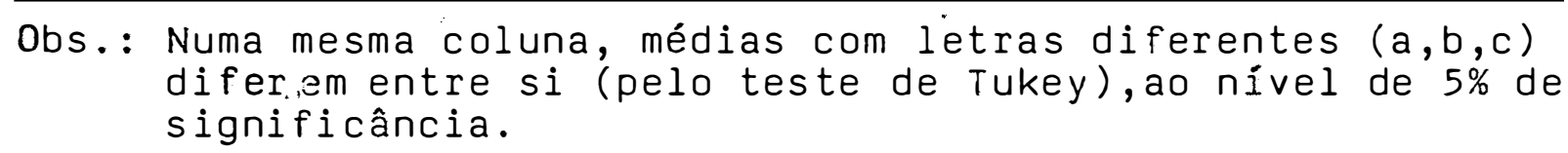 } \\
\hline \multicolumn{4}{|c|}{$\begin{array}{l}\text { (*) Média do período de comparação, com } 72 \text { dias de duração } \\
(* *) \text { Média dos últimos } 42 \text { dias do experimento (consumo estabi } \\
\text { GPD }=\text { Ganho de peso diário. }\end{array}$} \\
\hline
\end{tabular}


Em ambos esses periodos foram encontradas diferenças significativas a favor da Ração 60 , em comparação com a Ração $60 \mathrm{~T}$, demonstrando a superioridade do bagaço auto-hidrolisado sobre o bagaço "in natura" como alimento componente de rações completas para bovinos confinados. Não foram encontradas diferenças significativas entre os ganhos de peso proporcionados pelas Rações $40, .50$ e 60, durante o periodo de comparação. Porém, após a estabilização do consumo (últimos 42 dias) a Ração 60 mostrou-se superior às outras duas, proporcionando ganho de peso médio de 1,160 kg/cab.dia. Isto pode ter sido resultado de crescimento compensatório uma vez que este lote apresentou consumo inferior aos outros dois durante as primeiras 3 semanas da comparação.

Para os 72 dias do periodo de comparação, não houve tendência linear ou quadrática dos niveis de bagaço na ração sobre o ganho de peso dos lotes. Isto indica que as ra ções 40,50 e 60 foram equivalentes em termos de desempenho dos bovinos. A análise de variância indicou diferença significativa para o ganho de péso da Ração $60 \mathrm{~T}$ quando comparada com as outras três rações em conjunto.

A Tabela 16 apresenta o consumo e a conversão alimentar verificados para as quatro rações completas. Observar que, apesar de as diferenças de consumo entre as rações com bagaço auto-hidrolisado e com bagaço "in 
Tabela 16 - Parâmetros de eficiência nutricional dos bovinos alimentados com as rações completas à base de BAH $17 / 5$ ou bagaço "in natura".

\begin{tabular}{|c|c|c|c|c|}
\hline Parâmetro & Ração 40 & Ração 50 & Ração 60 & Ração 60T \\
\hline \multicolumn{5}{|l|}{$\begin{array}{l}\text { Consumo } \\
(\mathrm{kg} \mathrm{MS} / 100 \mathrm{~kg} \mathrm{PV})\end{array}$} \\
\hline - de 21/02 a 03/05 & 2,76 & 2,79 & 2,79 & 1,84 \\
\hline - de $22 / 03$ a 03/05 & 2,99 & 3,08 & 3,18 & 1,94 \\
\hline \multicolumn{5}{|l|}{$\begin{array}{l}\text { Conversão Alimentar } \\
\text { (kg MS cons./kg GPV) }\end{array}$} \\
\hline - de 21/02 a 03/05 & 10,33 & 12,25 & 11,62 & 9,60 \\
\hline - de $22 / 03$ a 03/05 & 11,39 & 12,20 & 10,15 & 11,75 \\
\hline
\end{tabular}

natura" terem sido notáveis, a conversão alimentar foi semelhan te entre todos os tratamentos.

Supomos que isto tenha ocorrido em função da curta duração do experimento e do relativamente longo período decorrido até à estabilização do consumo das rações à base de BAH 17/5. Observe-se que a adaptação à ração à base de bagaço "in natura" (RAÇão 60T) foi mais rápida, com o consumo estabí lizando-se já na segunda semana, conforme se percebe na figura 7. Este pode ser um dos fatores que concorreu para a conversão alimentar da RAÇÃO 60T ter sido semelhante à da RAÇÃO 60. 
Além disso sabe-se que em niveis de consumo menores, como os registrados para a RAÇÃO 60T, a digestibilidade da MS aumenta e, consequentemente, também a conversão alimentar (SCHNEI DER e FLATT, 1975). Outro aspecto a ser considerado é que o bagaço "in natura" utilizado havia sofrido processo de ensilagem, o que também pode promover pequeno acréscimo na diges tibilidade de materiais lignocelulósicos (JACKSON, 1978).

O bagaço "in natura" tem densidade baixa e, na proporção de 60 \% da M.S., provocou retração do consumo da RAÇÃo 60T. Provavelmente, ocorreu limitação física do consumo devido ao enchimento do trato disgestivo com um material muito volumoso e pouco denso.

Após a estabilização do consumo, atingiu-se uma ingestão diária de $\mathrm{BAH} 17 / 5$ da ordem de 4,76, 5,93 e 7,25 $\mathrm{kg}$ MS/cab./dia para as rações 40,50 e 60, respectivamente. $\mathrm{Na}$ RAÇÃo 60T, o consumo de bagaço "in natura" foi da ordem de 4,46 kg MS/cabeça/dia.

Os dados de consumo e conversão alimentar não puderam ser analisados estatisticamente, pois não foram regí trados individualmente para cada parcela. Como a alimentação foi em grupo, somente foi possivel obter os dados médios de consumo de cada lote. 
5. CONCLUSÕES

1. A utilização do processo de auto-hidrólise para tratamento do bagaço de cana é viável junto a usinas e destilarias, devido à disponibilidade de vapor à alta pres são e de facilidades operacionais.

2. Existem combinações especificas de pressão e tempo de tratamento que proporcionam os maiores incrementos na digestibilidade "in vitro" do bagaço. De uma maneira geral, quanto maior a pressão de tratamento, mais elevado é o valor de digestibilidade que se pode alcançar, menor é o tem po necessário para tal, e mais estreito é o patamar (interva lo entre tempos de tratamento) em que se obtém os melhores resultados.

3. O bagaço auto-hidrolisado é um material es tável, que pode ser armazenado por pelo menos 3 meses em pilhas compactadas e cobertas por lona plástica. É apropriado 
para fornecimento. na forma.de ração completa, pois pode ser fạ cilmente misturado com outros alimentos volumosos e com con centrados.

4. É necessário um periodo de 3 a 4 semanas pa ra ocorrer a estabilização do consumo de dietas que contém ele vada proporção de bagaço auto-hidrolisado. Este, ao contrário do bagaço "in natura", não restringe o nível de consumo das rações e o seu consumo atinge valores atribuidos a alimentos volumosos de boa qualidade.

5. Nos niveis testados, o bagaço auto-hidrolisado substituiu a cana picada da ração, sem provocar altera ções no consumo, ganho de peso e conversão alimentar dos bovi nos confinados.

6. A Ração 60 ( $60 \%$ de BAH $17 / 5$ na matéria seca) apresentou consumo $(+64 \%)$ e ganho de peso $(+89 \%)$ superiores aos da Ração 60 T (60\% de bagaço "in natura" na matéria seca), após a estabilização do consumo.

7. São necessárias mais investigações sobre es se alimento. A caracterização detalhada das reações químicas ocorridas durante o tratamento, determinações de digestibilidade "in vivo", trabalhos a nível de rúmem, ensaios com ou- 
56.

tras categorias animais, como vacas em lactação, e estudos pa ra desenvolvimento de métodos de conservação e processamento do bagaço auto-hidrolisado, são assuntos que ainda demandam pesquisa para o melhor conhecimento deste recurso forrageiro. 


\section{LITERATURA CITADA}

CAMPBELL, C.M.; O. WAYMAN;R.W. STANLEY; L.S.KAMSTRA; S.E. OL BRICH; E.B.HO-A e T. NAKAYAMA, 1973. Effects of pressure treatment of sugar cane bagasse upon nutrient utilization. Proc. Wistern Sec. ASAS. EUA, 24: 178-184.

CAMPOS, O.F.; J.F.C. SILVA; H.VILELA e A.A.souza, 1977. Valor nutritivo da raspa da mandioca e do bagaço de cana para ru minantes. Revista Ceres. 24(135): 521-529.

DESCHAMPS, A.M.; G. MAHOUDEAU e J.M. LEBEAULT, 1980. Fast degradation of kraft lignin by bacteria. European J. Appl. Microbiol. Biotechnol. 9 : 45-51.

DEVLIN, R.M., 1969. Plant Physiology. 2a ed. New York, EUA, Van Nostrand Reinhold Company Ltd. $446 \mathrm{p}$. 
GARRET, W.N.; H.G. WALKER Jr.; G.O. KOHLER; M.R. HART E R.P. GRAHAM, 1981. Steam treatment of crop residues for increa sed ruminant digestibility. II. Lamb Feeding Studies. J. Anim. Sci. 51(2): 409-413.

GOODING, E.G.B., 1982. Efeito de la calidad de la cana sobre su valor como alimento para bovinos. Producción Tropical Animal. 7: 76-97.

GOSSELINK, G.B.j., 1982. Ruptura da lignina da palha através de tratamento com uma solução de uréia. Holanda, Bureau de Agronomia da Indústria Holandesa de Adubos. Relatório no 17. $68 \mathrm{p}$.

HART, M.R.; H.G. WALKER Jr.; R.P. GRAHAM; P.J. GRAHAM; P.J.HAN NI; A.H. BROWN e G.O. KOHLER, 1981. Steam treatment of crop residues för increased ruminant digestibility. I. Effects of process parameters. J.Animal. Sci. 51(2): 402-408.

JACKSON, M.G., 1978. Treating straw for animal feeding. Anim. Prod. and Health Paper 10. Roma, Itália, FAO, 81 p.

JOSHI, A.L. e D.V.RANGNEKAR, 1979. Sugar cane bagasse based feed for growing cross-bred cattle. Indian Vet. J. 56: 5357 . 
MACHADO, O.L.T., 1982. Descompressão rápida como pré-trata mento de madeira para a hidrólise enzimática. Rio de Janeiro UFRJ/Instituto de Química. 80 p. (Tese de Mestrado).

MARCOS, A.C.M.; P.R. LEME e C. BOIN, 1984. Efeito do tempo de tratamento a pressão de vapor na composição química e na digestibilidade "in vitro" da matéria seca do bagaço de ca na-de-açúcar. Zootecnia. Nova Odessa, SP. 22(4): 383-395.

MC DONALD, P; R.A. EDWARDS e J.F.D. GREENHALGH, 1977. Animal Nutrition. 2a ed. New York, EUA, Longman Group Ltd. 479 p.

PACOLA, L.J.; A.G. RAZOOK e F.P. LIMA, 1977. Aproveitamento do bagaço de cana-de-açúcar na engorda de bovinos confinados. B. Indústria anim. Nova Odessa, SP. 34(1): 25-28.

PATE,F.M., 1982. Value of treating bagasse with steam under pressure for cattle feed. Trop. Agric. Trinidad. 59(14): 293-297.

PIMENTEL GOMES, F., 1978. Curso de Estatistica Experimental . 8a ed., Piracicaba, SP. Livraria Nobel S.A., 430 p.

PINTO, L.A., 1983. O valor do bagaço como combustivel. In: Avaliação do bagaço de cana-de-açúcar. Coleção SOPRAL no 4. São Paulo. SOPRAL, P. 10-21. 
RANDEL, P.F., 1970. Ad libitum feeding of either a complete ration based on sugar cane bagasse or a conventional concentrates mixture to dairy cows. J. Agric. Univ. Puerto Rico. Rio Piedras, Porto Rico. 54(3): 429-443.

RANGNEKAR, D.V.; V.C. BADVE; S.T. KHARAT; B.N. SOBALE E A.L. JOSHI, 1982. Effect of high-pressure steam treatment on chemical composition and digestibility in vitro of rougha ges. Anim. Feed Sci. Technol. Amsterdam, Holanda, 7: 6170 .

ROMAN-PONCE, H.; H.H. VAN HORN; S.P. MARSHALL; G.J. WILCOX E P.F. RANDEL, 1975. Complete rations for dairy cattle. V. Interaction of sugarcane bagasse quantity and form with soybean meal, urea and starea. J.Dairy Sci. Champaign I11., EUA. 58(9): 1320-1327.

SCHNEIDER, B.H. e W.P. FLATT, 1975. The evaluation of feeds through digestibility experiments. Athens, Georgia, EUA. The University of Georgia Press. $423 \mathrm{p}$.

SILVEIRA, A.C., 1971. Efeito da maturidade sobre a composição em fibra, celulose, lignina e silica e digestibilidade "in vitro" do capim Napier e soja Perene. Piracicaba, ESALQ/USP, $99 \mathrm{p.}$ (Tese de Doutoramento). 
TAYLOR, J.D. e W.J. ESDALE (s.d.). Increased utilization of crop residues as animal feed through autohydrolysis. Ottawa, Canadá. Stake Technology. 6 p.

Van SOEST, P.J. e L.A. MOORE, 1965. New chemical methods for analyses of forages for the prediciting nutritive value. Proc. IX International Gassland Congress. $1974 \mathrm{p}$.

Van SOEST, P.J., 1982. Nutritional ecology of the ruminant. Corvallis, Oregon, EUA. O e B. Books Inc. $374 \mathrm{p}$.

ZADRAZIL, F., 1980. Conversion of different plant waste into feed by basidiomycetes. European J. Appl. Microbiol.Biotechnol. 9: 243-248.

ZADRAZIL, F. e H. BRUNNERT, 1980. The influence of ammonium nitrate supplementation on degradation of straw colonized by higher fungi. European J. Appl. Microbiol. Biotechnol. $9: 37-44$.

ZEGARRA, J.R., 1978. Perspectivas del aprovechamento del bafazo de la caña de azúcar. Tecnologia. México, D.F. Boletim no 5, $19 \mathrm{p}$. 